Article

\title{
Combined Use of Diagnostic Fumarate Addition Metabolites and Genes Provides Evidence for Anaerobic Hydrocarbon Biodegradation in Contaminated Groundwater
}

\author{
Gurpreet Kharey ${ }^{(}$, Gabrielle Scheffer and Lisa M. Gieg *(D) \\ Department of Biological Sciences, University of Calgary, 2500 University Drive NW, Calgary, AB T2N 1N4, \\ Canada; gurpreet.kharey@mail.mcgill.ca (G.K.); gabrielle.scheffe1@ucalgary.ca (G.S.) \\ * Correspondence: lmgieg@ucalgary.ca; Tel.: +1-403-210-7207
}

Received: 14 September 2020; Accepted: 28 September 2020; Published: 6 October 2020

check for updates

\begin{abstract}
The widespread use of hydrocarbon-based fuels has led to the contamination of many natural environments due to accidental spills or leaks. While anaerobic microorganisms indigenous to many fuel-contaminated groundwater sites can play a role in site remediation (e.g., monitored natural attenuation, MNA) via hydrocarbon biodegradation, multiple lines of evidence in support of such bioremediation are required. In this study, we investigated two fuel-contaminated groundwater sites for their potential to be managed by MNA. Microbial community composition, biogeochemical indicators, fumarate addition metabolites, and genes diagnostic of both alkane and alkyl-monoaromatic hydrocarbon activation were assessed. Fumarate addition metabolites and catabolic genes were detected for both classes of hydrocarbon biodegradation at both sites, providing strong evidence for in situ anaerobic hydrocarbon biodegradation. However, relevant metabolites and genes did not consistently co-occur within all groundwater samples. Using newly designed mixtures of quantitative polymerase chain reaction (qPCR) primers to target diverse ass $A$ and $b s s A$ genes, we measured ass $A$ gene abundances ranging from $10^{5}-10^{8}$ copies $/ \mathrm{L}$, and $b s s A$ gene abundances ranging from $10^{5}-10^{10}$ copies/L at the sites. Overall, this study demonstrates the value of investigating fuel-contaminated sites using both metabolites and genes diagnostic of anaerobic hydrocarbon biodegradation for different classes of hydrocarbons to help assess field sites for management by MNA.
\end{abstract}

Keywords: hydrocarbon-contaminated groundwater; anaerobic biodegradation; hydrocarbon bioremediation; fumarate addition metabolites; ass $A$ gene; bss $A$ gene

\section{Introduction}

The use of petroleum-based fuels to serve our global energy needs has resulted in the contamination of many pristine environments with hydrocarbons due to failing infrastructure or accidental spills. Hydrocarbons, compounds that are composed solely of carbon and hydrogen, are the primary components of refined fuel mixtures such as gasoline and diesel. Such mixtures are often stored in metal tanks either above-ground or underground which can corrode, potentially leaking hydrocarbons into the environment. Once introduced to groundwater, hydrocarbon contaminants can be carried away from the source due to groundwater flow and potentially enter drinking water sources, other bodies of water, or housing infrastructure. Exposure to these chemicals may lead to the development of chronic illnesses, such as nasal and renal cancers, leukemia, and lower quality of life [1,2].

Research within the last 3 decades has clearly demonstrated that microorganisms inhabiting anoxic environments such as deep subsurface petroliferous reservoirs and shallow groundwater 
aquifers can utilize hydrocarbons as their carbon and energy sources [3-5]. In the absence of oxygen that serves as both a terminal electron acceptor and a powerful oxidant, anaerobic microorganisms employ distinct mechanisms for overcoming the stability of hydrocarbons for use as carbon and energy sources [6]. For unsubstituted hydrocarbons, such as benzene, naphthalene, or phenanthrene, evidence is increasingly pointing to carboxylation as an important activation step [7-10], although the mechanism is not fully understood. Alkyl-substituted monoaromatic hydrocarbons (such as toluene, ethylbenzene, and xylene, [TEX]), alkyl-substituted polycyclic aromatic compounds (PAHs), and $n$-alkanes are activated by addition to fumarate [5,6], aside from a few exceptions [11]. This mechanism, commonly referred to as 'fumarate addition', is the most well-studied mechanism of hydrocarbon activation under anoxic conditions, and will be the focus of the work described here.

To date, three fumarate addition enzymes (FAEs) have been characterized to varying extents. Benzylsuccinate synthase (BSS) catalyzes the addition of fumarate to toluene $[12,13]$ and potentially, closely related alkylated monoaromatic hydrocarbons such as $o_{-}, m-$, and $p$-xylene and ethylbenzene [14,15]. Alkylsuccinate synthase (ASS, also known as 1-methylalkylsuccinate synthase, MAS) catalyzes the addition of the subterminal carbon of an alkane to the double bond of fumarate, forming an 'alkylsuccinate' $[16,17]$. Naphthylmethylsuccinate synthase (NMS) is the presumed paralog to BSS catalyzing fumarate addition to methyl-substituted PAHs [18]. These reactions, best understood for BSS and ASS, produce initial 'succinate' intermediates that are further metabolized by beta-oxidation-like reactions. Genes for catalytic subunits of these enzymes, denoted as bss $A$ or ass $A$ $(\operatorname{mas} D)$, have also been identified $[14,16,17,19]$, and are known to be highly diverse across multiple environments and clades [19-24].

Many techniques can be used to determine whether a hydrocarbon-contaminated groundwater site is undergoing in situ bioremediation [25] and it is critical to use a combined approach to provide multiple lines of evidence in support of such natural attenuation $[4,26]$. Since being proposed as unique indicators of anaerobic hydrocarbon biodegradation in contaminated groundwater [27], fumarate addition metabolites have been detected at many fuel-impacted field sites [5]. As these metabolites have a specific relationship to their parent hydrocarbon and are not found in fuel mixtures, their detection in contaminated groundwater provides strong evidence that the associated microbial community members are capable of in situ anaerobic hydrocarbon biodegradation. However, the transient nature of these biodegradation pathway intermediates can make their detection difficult as they rarely accumulate to higher than nanomolar concentrations in situ [5,28]. As an alternate approach, polymerase chain reaction (PCR)-based assays targeting a dedicated gene that encodes a subunit of BSS (or more rarely, ASS) have also been applied to contaminated groundwater aquifers to indicate anaerobic hydrocarbon degradation potential via fumarate addition [19,29-32]. These assays only measure the potential for fumarate addition, as the presence of or quantity of a gene (e.g., number of copies per unit volume) does not denote its actual expression or the activity of the translated protein [4]. Two previous studies have sought both fumarate addition metabolites and associated genes as biomarkers to garner evidence for anaerobic hydrocarbon biodegradation in groundwater environments, focussing on the $b s s A$ gene [30,32]. Oka et al. [32] detected the $b s s A$ gene at one well location, while metabolites were detected in multiple wells at the contaminated groundwater site under study. Using two test lanes (distinct paths of groundwater flow) to examine the effects of ethanol (a gasoline oxygenate) on benzene, toluene, and $o$-xylene biodegradation (one lane injected with ethanol and BTX, one lane injected with BTX only), Beller et al. [30] detected $b s s A$ genes in all groundwater wells tested. However, fumarate addition metabolites were primarily detected only in the ethanol-supplemented lane, presumably because the presence of this labile substrate led to slower rates of hydrocarbon biodegradation and higher benzylsuccinate concentrations [30]. Both of these studies showed that interrogating contaminated sites for both known biodegradation genes and metabolites can help to overcome the limitations of using one approach alone in order to provide evidence in support of in situ hydrocarbon biodegradation. 
In this study, we evaluated two hydrocarbon-contaminated groundwater sites for their potential to be managed by in situ bioremediation (e.g., by monitored natural attenuation, MNA) by investigating each site using multiple approaches that included measurements of fumarate addition metabolites and FAE genes. Metabolites and genes diagnostic of both anaerobic alkane and alkyl-monoaromatic hydrocarbon biodegradation were sought. As part of this study, we also designed new quantitative polymerase chain reaction (qPCR) primer mixtures for broad capture of both ass $A$ and bss $A$ genes, and used these to quantify these biodegradation genes in groundwater samples. As the two sites examined were distinct in their levels of hydrocarbon concentrations (comparatively low and high), the study also provided the opportunity to assess whether there were any relationships between biodegradation gene abundances and hydrocarbon concentrations.

\section{Materials and Methods}

\subsection{Site Descriptions}

The two hydrocarbon-contaminated sites under study (designated Site A and Site B) are located in Alberta, Canada. Both field sites are former gasoline and diesel storage and dispensing stations that leaked these fuel mixtures into their underlying shallow groundwater aquifers. For Site A (Figure 1), a leak was initially discovered in the early 1990s in an above-ground fuel storage tank. The bulk fuel facility was decommissioned in 2003. Land farming and other in situ bioremediation efforts were undertaken at least 10 years prior to this investigation yielding inconclusive clean-up results due to limited sampling. The geology of Site A is considered predominantly clayey-silt, with groundwater levels averaging 1.4 metres below ground surface (mBGS), underlain by bedrock at $\sim 2$ mBGS. Groundwater flow is generally towards the northeast (Figure 1). Site B (Figure 2) is primarily clay to silty-clay in composition, with groundwater levels ranging between $0.5-1.7 \mathrm{mBGS}$. Hydrocarbon releases occurred from above ground and underground storage tanks at different times, resulting in two hydrocarbon plumes and complex groundwater flow patterns, though groundwater flow was generally eastward (towards structures shown on right of the Figure 2 schematic). Numerous undisclosed remediation strategies had been used at Site B prior to the initiation of this study. Both sites were selected for study by industry partners as they were potential candidates for monitored natural attenuation or other bioremediation approaches but had not been microbiologically characterized. Twelve groundwater monitoring wells, that included both non-contaminated and hydrocarbon-contaminated locations, were selected from each site for the study based on prior monitoring efforts.

\subsection{Sample Collection}

Groundwater sampling was carried out by initially removing $6 \mathrm{~L}$ of groundwater to purge the wells. Two $1 \mathrm{~L}$ volumes of water sample from each groundwater well were then taken, completely filling $1 \mathrm{~L}$ glass bottles to minimize air ingress. One bottle contained $5 \mathrm{~mL} 6 \mathrm{M} \mathrm{HCl}$ such that the water sample became acidified to $\mathrm{pH} 2$; this bottle was used for hydrocarbon metabolite analysis. The other bottle was left unchanged, and was used for hydrocarbon biodegradation gene analysis and microbial community profiling. A 'trip blank', composed of tap water (municipal drinking water), was included at sampling events to account for any background hydrocarbon contamination due to sampling vessels or equipment. All sample bottles were placed on ice and transported to the University of Calgary. Upon arrival, all sample bottles were kept at $4{ }^{\circ} \mathrm{C}$ until they were processed. Samples for hydrocarbon measurements were taken at the same time but in separate collection vessels, and concentrations were measured by a third party (AGAT Laboratories, Calgary, AB; conducted in 2016 only based on limited resources). Nitrate and sulfate concentrations were measured by ion chromatography [33], while Fe(II) levels were measured using the ferrozine assay [34]. 


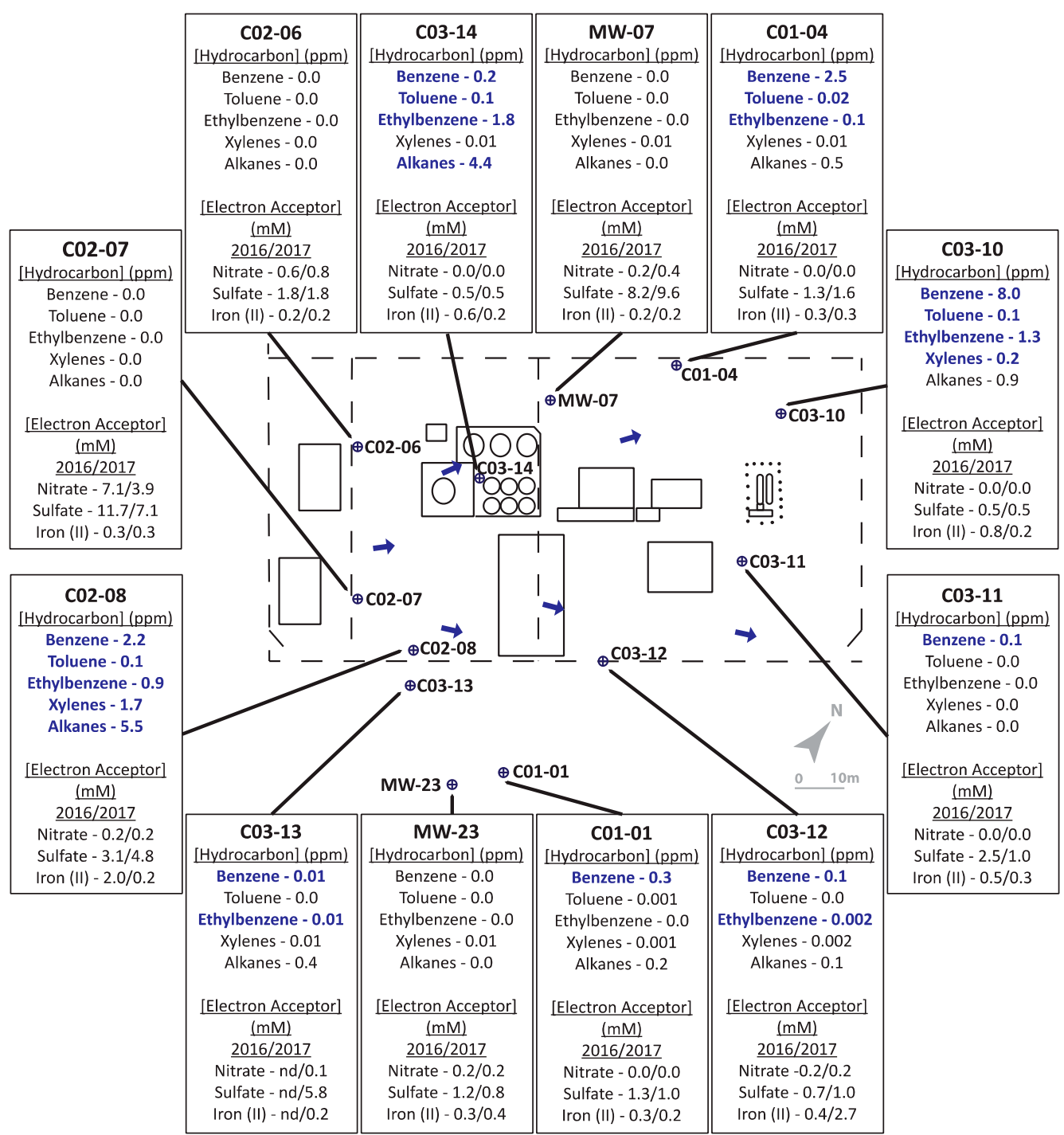

Figure 1. Schematic of Site A, with pop-outs summarizing hydrocarbon concentrations (analyzed in 2016 only) and indicators of potential electron accepting processes (analyzed in 2016 and 2017). Bolded text indicates hydrocarbon concentrations above allowable limits for hydrocarbons in non-drinking groundwater sources. 'nd' = no data available as well was not sampled.

\subsection{Hydrocarbon Metabolite Analysis}

Acidified groundwater samples were extracted and processed for hydrocarbon metabolite analysis as previously described [35]. Briefly, ethyl acetate was used as the organic solvent, and concentrated extracts were silylated using $\mathrm{N}, \mathrm{O}$-bis(trimethylsilyl)trifluoroacetamide. These prepared samples were analyzed by gas chromatography coupled with mass spectrometry (GC/MS) as per reported methods [35]. Qualitative identification of alkylsuccinates were identified based on characteristic MS fragmentation ion profiles [5,36]. Benzylsuccinate was identified based on GC retention time and mass spectral comparison to a commercially-available standard (Alfa Aesar, Tewksbury, MA, USA), while synthesized $m$-methylbenzylsuccinate and ethylbenzylsuccinate [36] were used to identify fumarate addition metabolites from xylenes and ethylbenzene, respectively. 


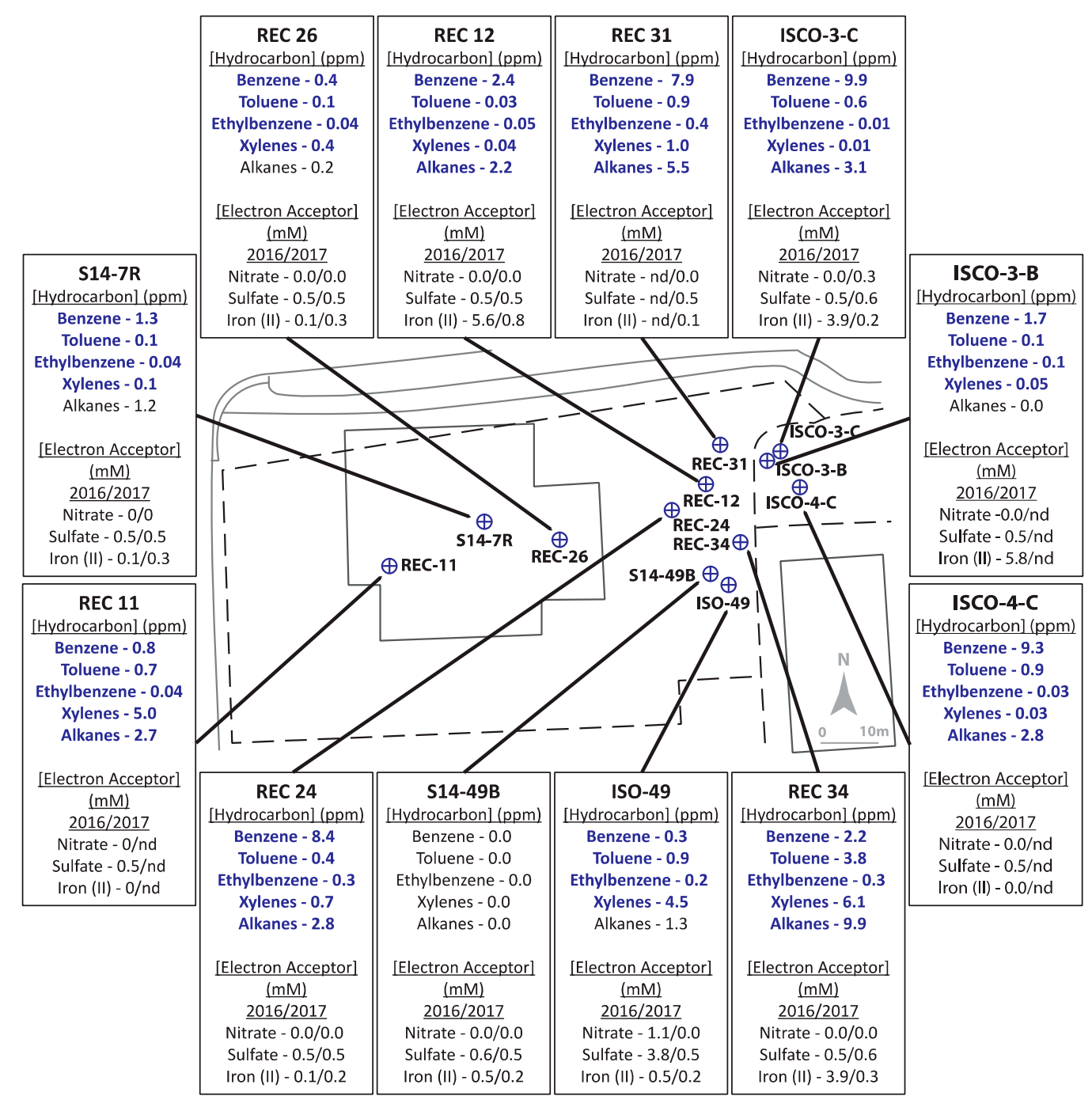

Figure 2. Schematic of Site B, with pop-outs summarizing hydrocarbon concentrations (analyzed in 2016 only) and indicators of potential electron accepting processes (analyzed in 2016 and 2017). Bolded text indicates hydrocarbon concentrations above allowable limits for hydrocarbons in non-drinking groundwater sources. 'nd' = no data available as well was not sampled.

\subsection{Biomass Collection and DNA Extraction}

Non-acidified samples were centrifuged at 10,000 rpm for $10 \mathrm{~min}$ using a Beckman Coulter Avanti J-E series centrifuge unit (Beckman Coulter, Brea, CA, USA). Collected pellets were re-suspended in approximately $10 \mathrm{~mL}$ of supernatant and stored at $-80^{\circ} \mathrm{C}$. DNA from pellet biomass was extracted using the MP Bio FastDNA Extraction Kit for Soil (MP Biomedicals, Solon, OH, USA) as per the manufacturer's instructions. Extracted gDNA was quantified using fluorometry (Qubit 2.0 fluorometer; sample volume $1 \mu \mathrm{L}$ ). Sample gDNA concentrations were not normalized to preserve possible less abundant taxa.

\subsection{S rRNA Gene Analysis for Microbial Community Profiling}

Microbial community analysis was done using the same DNA preparation procedure as described above. Microbial community composition was assessed using Illumina MiSeq sequencing of the V6-V8 hypervariable region, amplified using primers Illumina926f (TCGTCGGCAGCGTCAGAT GTGTATAAGAGACAGAAACTYAAAKGAATTGRCGG) and Illumina1392r (GTCTCGTGGGCTCGG AGATGTGTATAAGAGACAGACGGGCGGTGTGTRC) [37]. Amplification was undertaken using the 
following protocol: first-round PCR reactions contained: $12.5 \mu \mathrm{L}$ polymerase mastermix (Fermentas Taq (ThermoFisher Scientific, Waltham, MA, USA) or KAPA Hi-Fi (Roche, Basel, Switzerland), $0.5 \mu \mathrm{L}$ each forward and reverse primer $(200 \mathrm{nM}), 1,2,5$, or $10 \mu \mathrm{L}$ of DNA template, with remaining volume of PCR-grade water up to $25 \mu \mathrm{L}$ final volume. Second-round PCR reactions contained: $25 \mu \mathrm{L}$ polymerase mastermix (Fermentas Taq or KAPA Hi-Fi), $1 \mu \mathrm{L}$ each of forward and reverse primer (Illumina NexteraXT Indexes (Illumina, San Diego, CA, USA); $200 \mathrm{nM}$ ), $10 \mu \mathrm{L}$ of purified first-round DNA amplicon, and $13 \mu \mathrm{L}$ of PCR-grade water for a total reaction volume of $50 \mu \mathrm{L}$. Thermocycling conditions for both first- and second-round amplification were as described in Toth and Gieg [35], using either Fermantas Taq polymerase or KAPA Hi-Fi polymerase. Purifications of the first- and second-round PCR amplicons were undertaken using AMPure Magnetic beads or a Qiagen PCR Purification kit (AMPure: Beckman Coulter, Brea, CA; Qiagen, Hilden, Germany). Samples were then normalized to $2 \mathrm{ng} / \mu \mathrm{L}$ and pooled into a sequencing library. Samples were loaded onto the Illumina MiSeq sequencing platform $(2 \times 300)$ kit at the International Microbiome Centre (University of Calgary, Calgary, Alberta, Canada). The resulting sequencing reads were assembled using PEAR 0.9.6 (50 bp overlap, $350 \mathrm{bp}$ truncation) and given taxonomic rank through MetaAmp Version 2.0 using the SILVA 132 database at a species $97 \%$ similarity cutoff $[38,39]$. Microbial community analyses were undertaken using a $2 \%$ relative read abundance cut-off. This was done to limit the amount of less abundant reads, ultimately simplifying the analysis to the most highly abundant taxa. 16S rRNA gene sequences have been deposited in the NCBI Short Read Archive (SRA) database with assigned accession numbers SAMN 15459469 to SAMN 15459510.

\subsection{Qualitative and Quantitative Assays for assA and bssA Genes}

Assaying field samples for the presence/absence of the ass $A$ and $b s s A$ genes (i.e., qualitative detection) through PCR was done using primer sets and thermocycling conditions as previously reported [19,20,22,40]. Primer sets used to interrogate all field samples were: ass $A=7757 \mathrm{af} / 8543 \mathrm{r}$ [22]; $b s s A=7772 \mathrm{f} / 8546 \mathrm{r}$ [19]. The protocol for the assay was as follows: $12.5 \mu \mathrm{L}$ of KAPA Hi-Fi PCR MasterMix, $10.5 \mu \mathrm{L}$ PCR-grade $\mathrm{H}_{2} \mathrm{O}, 0.5 \mu \mathrm{L}$ each of forward and reverse primer $(200 \mathrm{nM})$, and $1 \mu \mathrm{L}$ of gDNA template. Confirmation of amplification was undertaken using gel electrophoresis ( $1 \%$ agarose) by comparing PCR products with the $b s s A$ or ass $A$ gene amplified from organisms known to harbour these genes (ass A, Desulfospirillum alkenivorans AK-01 [16]; bss A, Thauera aromatica [12]) as positive controls. Amplicons were Sanger sequenced, and their identities were confirmed via BLASTn.

Quantification assays targeting the $a s s A$ and $b s s A$ genes were performed using newly designed qPCR primer mixtures (Table 1). Details regarding primer design and validation/comparison against published primer sets are described in the Supplementary Materials. Primer mixtures used for ass $A$ gene quantification contained an equimolar mixture of forward primers assOri, assMsd, assEx, and assSml, with reverse primer 8543r, with an amplicon length of $486 \mathrm{bp}$ (Table 1). Likewise, bss $A$ gene quantification used a forward primer mixture containing an equimolar mixture of forward primers bssOil, bssMys, bssSuf, and bssWin, with reverse primer bssHitr, resulting in an amplicon length of $141 \mathrm{bp}$ (Table 1). The qPCR protocol was as follows: $12.5 \mu \mathrm{L}$ of KAPA Hi-Fi PCR MasterMix, $10.5 \mu \mathrm{L}$ PCR-grade $\mathrm{H}_{2} \mathrm{O}, 0.5 \mu \mathrm{L}$ each of forward and reverse primer mixtures $(200 \mathrm{nM})$, and $1 \mu \mathrm{L}$ of gDNA template. Quantification was conducted using a Bio-Rad CFX96 thermocycler, with analysis using the Bio-Rad CFXManager software, running a single threshold $\mathrm{Cq}$ evaluation. Thermocycling conditions for the ass A qPCR assay were as follows: $95^{\circ} \mathrm{C}$ for $3 \mathrm{~min}, 39$ cycles of $95^{\circ} \mathrm{C}$ for $15 \mathrm{~s}, 62{ }^{\circ} \mathrm{C}$ for $25 \mathrm{~s}$ (each cycle ending with a plate read), $62{ }^{\circ} \mathrm{C}$ for $2 \mathrm{~min}$, followed by a melt curve $\left(65^{\circ} \mathrm{C}\right.$ to $95^{\circ} \mathrm{C}$, increasing in $0.5^{\circ} \mathrm{C}$ increments, held for $5 \mathrm{~s}$, then plate read). The annealing temperature for $b s s A$ was adjusted to $65^{\circ} \mathrm{C}$ otherwise following the same method. Amplicons used for generating standard curves were amplified using the 7772f/8546r primers [19] and gel extracted (Qiagen Gel Extraction Kit, Qiagen, Hilden, Germany) in preparation for use in a 7 log standard curve (1:10 serial dilution). Amplicon sequences were confirmed via Sanger sequencing. All qPCR amplicons were verified using the same gel electrophoresis method as described above for qualitative ass $A$ and $b s s A$ 
analysis, but instead using the ass $A$ and $b s s A$ qPCR primers. Those samples that did not have the appropriate length DNA bands were not included in subsequent analyses.

Table 1. Primers designed and used in this study for quantitative detection of the $\operatorname{bs} A$ and ass $A$ genes in Site A and B groundwater samples. Melting temperature $\mathrm{T}_{\mathrm{m}}$ was calculated via the IDT OligoAnalyzer 3.1 online tool using default quantitative polymerase chain reaction (qPCR) parameters.

\begin{tabular}{llcc}
\hline \multicolumn{1}{c}{ Name } & \multicolumn{1}{c}{ Sequence $\left(\mathbf{5}^{\prime} \mathbf{3}^{\prime}\right)$} & Tm $\left({ }^{\circ} \mathbf{C}\right)$ & Reference \\
\hline bss $\boldsymbol{A}$ forward & & & \\
bssOil & GAA TCC CTG GTT ACA GGT CCA C & 64.1 & This study \\
bssMys & CAA TCC GTG GCA CAA CTG CAT G & 66.3 & This study \\
bssSuf & GAA TAC GTG GAG CGA CCC GCT C & 68.1 & This study \\
bssWin & CAA TCC GTG GCT TCA GGT TCA T & 65 & This study \\
bss $\boldsymbol{A}$ reverse & & & \\
bssHitr & TCC TCG TAG CCT TCC CAG TT & 64.6 & This study \\
ass $\boldsymbol{A}$ forward & & & This study \\
assOri & CTC CGC CAC GGC CAA CTG & 67.4 & This study \\
assMsd & CTC AGC CAC CGC CAA CTG & 65 & This study \\
assEx & CTC TGC GAC CGC GAA TTG & 63 & This study \\
assSml & TAG CGC CAC GGC CAA CTG & 67 & [22] \\
ass $\boldsymbol{A}$ reverse & TCG TCR TTG CCC CAY TTN GG & 65.7 & \\
8543r & TC & &
\end{tabular}

\subsection{Illumina Sequencing of assA and bssA Amplicons}

Those samples which matched the amplicon lengths of the standard curve amplicons using the newly designed primer mixtures were gel extracted (Qiagen Gel Extraction Kit). Primers containing the Illumina MiSeq adapter sequences (for addition of sequencing barcodes) were taken from $16 \mathrm{~S}$ rRNA gene primers commonly used in our studies (926f/1392r) [37] and added to the $5^{\prime}$ end of each primer constituting the primer mix for both ass $A$ and $b s s A$ genes. MiSeq primer mix was prepared to the same concentration as the qPCR primer mix $(20 \mu \mathrm{M})$. Thermocycling conditions were as described above for $16 \mathrm{~S}$ amplification. Second-round PCR amplicons were gel purified the same way as in the first round. Samples were then normalized and pooled into a $2 \mathrm{ng} / \mu \mathrm{L}$ library. ass $A$ amplicons were submitted to the International Microbiome Centre (University of Calgary) for Illumina sequencing (via $2 \times 300 \mathrm{bp}$ sequencing kit). bss $A$ amplicon sequencing was done at the University of Calgary Cumming School of Medicine Centre for Genomics and Informatics, using an Illumina MiSeq $150 \times 2 \mathrm{kit}$.

Resulting sequences were assembled using PEAR 0.9.6 (50 bp overlap, $350 \mathrm{bp}$ truncation) and analyzed through MetaAmp using the 'non-16S' option (which does not assign taxonomy) at 97\% similarity [38,39]. Resulting sequences were analyzed through BLASTn [41]. Sequences matching ass $A$ annotated sequences or those in whole genomes of putative alkane-degrading microorganisms were selected, disregarding any sequence that returned matches with $<70 \%$ coverage and identity. Sequences that passed this quality control step and thus selected for analysis were 6 of 86 for ass $A$ and 13 of 65 for $b s s A$. Examples of remaining sequences that were neither present in the genomes of putative alkane-degrading microorganisms, nor annotated as alkylsuccinate synthase, are shown in Table S4. Selected sequences were then compiled into a Multiple Sequence Alignment (MSA) in UGENE software and aligned using ClustalW to determine similarity to other sequenced reads [42]. A maximum likelihood dendrogram was built using approximate likelihood ratio test (aLRT) tree branch support (to estimate correct placement of internal branches) and a combination of nearest neighbor interchanges (NNI) and sub-tree pruning and regrafting (SPR) tree building methods (for initial tree building when choosing which possible tree is the most likely result from given nucleotide data) [43,44]. ass $A$ and bss $A$ amplicon sequences have been deposited in GenBank, with accession numbers MT722950 to MT722968. 


\section{Results}

\subsection{Hydrocarbons, Putative Electron Acceptors, and Microbial Community Profiles}

Several sampled wells collected from both sites A (Figure 1) and B (Figure 2) were characterized by BTEX (benzene, toluene, ethylbenzene, and xylenes (all isomers)) and alkane concentrations above the Alberta guidelines for allowable concentrations in non-drinking groundwater (benzene $=0.005 \mathrm{ppm}$ $(\mathrm{mg} / \mathrm{L})$; toluene $=0.024 \mathrm{ppm}$; ethylbenzene $=0.0016 \mathrm{ppm} ;$ xylenes (all isomers) $=0.02 \mathrm{ppm}$; alkanes = $2.2 \mathrm{ppm}$; [45]; see Table S1 in Supplementary Materials for tabulated hydrocarbon concentrations measured at both sites). Overall, Site A (Figure 1) groundwater samples were characterized by substantially lower hydrocarbon concentrations than Site B (Figure 2).

For Site A, hydrocarbon concentrations measured in the monitored wells in 2016 ranged between 0-8 ppm. Four of the 12 wells, located on the periphery of the site (MW-07, C02-06, C02-07, MW-23) were considered non-contaminated, as no hydrocarbons were detected above analytical limits. Well C03-10 contained the highest total BTEX concentration, while Wells C02-08 and C03-14 had the highest alkane concentrations. The remaining contaminated sampled wells contained comparatively lower, but detectable, hydrocarbon concentrations. In terms of the potential electron acceptors that were measured, one uncontaminated well contained substantial levels of nitrate (4-7 mM; well C02-07) while nitrate was comparatively low in all other contaminated wells and low or non-contaminated wells. Sulfate concentrations ranged from 5-12 mM in two of the non-contaminated wells (C02-07 and MW-07) but were lower (1-2 mM) in other non-contaminated wells (C02-06 and MW-23), suggesting that sulfate could serve as a potential electron acceptor in some locations at the site. Fe(II), the product of microbial Fe(III) reduction, was measured at less than $1 \mathrm{mM}$ in most sampled wells except at two locations: C02-08 with comparatively high hydrocarbon concentrations, and C03-12 with comparatively low hydrocarbon concentrations. While the biogeochemical measurements suggested that nitrate, sulfate, or iron reduction could be electron acceptors in different portions of the site, it was difficult to discern clear trends or patterns that relate hydrocarbon concentrations with anaerobic electron accepting processes across the site. This heterogeneity was further exemplified by the microbial community profiling results, where microbial community compositions were different in each well sampled (Figure 3). While some groundwater samples showed similar taxonomic profiles in 2016 and 2017 (such as C02-08 and C03-12), most had very different taxonomic profiles across the two years. The most consistently detected taxon in all samples collected from Site A in 2016 and 2017 was Rhodoferax, present in all wells in the range of 3-44\% (in 2016) and 5-62\% (in 2017) relative sequence abundance. Members of this genus are known to have nitrate- and iron-reducing abilities, aligning with some of the terminal electron acceptor data. Many of the taxa present in some of the contaminated well samples affiliate with known hydrocarbon degraders, such as Azoarcus, Geobacter, Polaromonas, and some members of the Burkholderiaceae and Rhodocyclaceae families. Although sulfate was present as a putative electron acceptor in some groundwater samples, sulfate-reducing microorganisms were not prevalent at $>2 \%$ relative abundance.

Site B was more highly contaminated site than Site A, with maximum total hydrocarbon concentrations reaching $\sim 35$ ppm (REC 34) with 7 wells above 10 ppm (ISCO-3-C, ISCO-4-C, ISO49, REC 11, REC 24, REC 31, and REC 34) (Figure 2, Table S1). Of the 12 wells sampled at Site B, only well S14-49B was non-contaminated, with all measured hydrocarbons below detection levels. The groundwater in all other wells surpassed the $0.005 \mathrm{ppm}$ benzene guideline, the 0.024 ppm toluene guideline, the $0.0016 \mathrm{ppm}$ ethylbenzene guideline, and the $0.02 \mathrm{ppm}$ xylenes guideline (except for well ISCO-3-C at 0.01 ppm xylenes). In 2016, all wells except ISCO-3-B and REC 26 were above the 2.2 ppm alkane guideline. Nitrate and sulfate concentrations for almost all samples collected from in Site B were at or below $0.5 \mathrm{mM}$, aside from one well (ISO-49 in 2016). Four contaminated wells (REC12, ISCO-3-C, ISCO-3-B, and REC34) had elevated Fe(II) concentrations (4-6 mM), suggesting that iron-reducing microorganisms may be present at the site. The single non-contaminated groundwater well (S14-49B) did not show substantial concentrations of measured electron acceptors. The microbial 
community profiles of Site B samples collected in 2016 and 2017 are shown in Figure 4. Similar to Site A, Rhodoferax was present in most groundwater samples analyzed, and the microbial community profiles were different in each well sampled (Figure 4). Several taxa detected in the contaminated wells are known to have members capable of hydrocarbon biodegradation, such as Burkholderiaceae, Xanthomonadaceae, Polaromonas, Geobacter, Acidovorax, and Desulfosporosinus. Distinct from Site A, some methanogens were detected in Site B samples, including Methanosaeta and Methanobacterium; these taxa were most abundant in the single non-contaminated groundwater sample at Site B, S14-49B, aligning with the low levels of other potential electron acceptors (Figures 2 and 4). As with Site A, no clear trends in hydrocarbon concentrations, potential electron acceptors, and taxonomic profiles could be discerned for Site B based on these measured parameters.

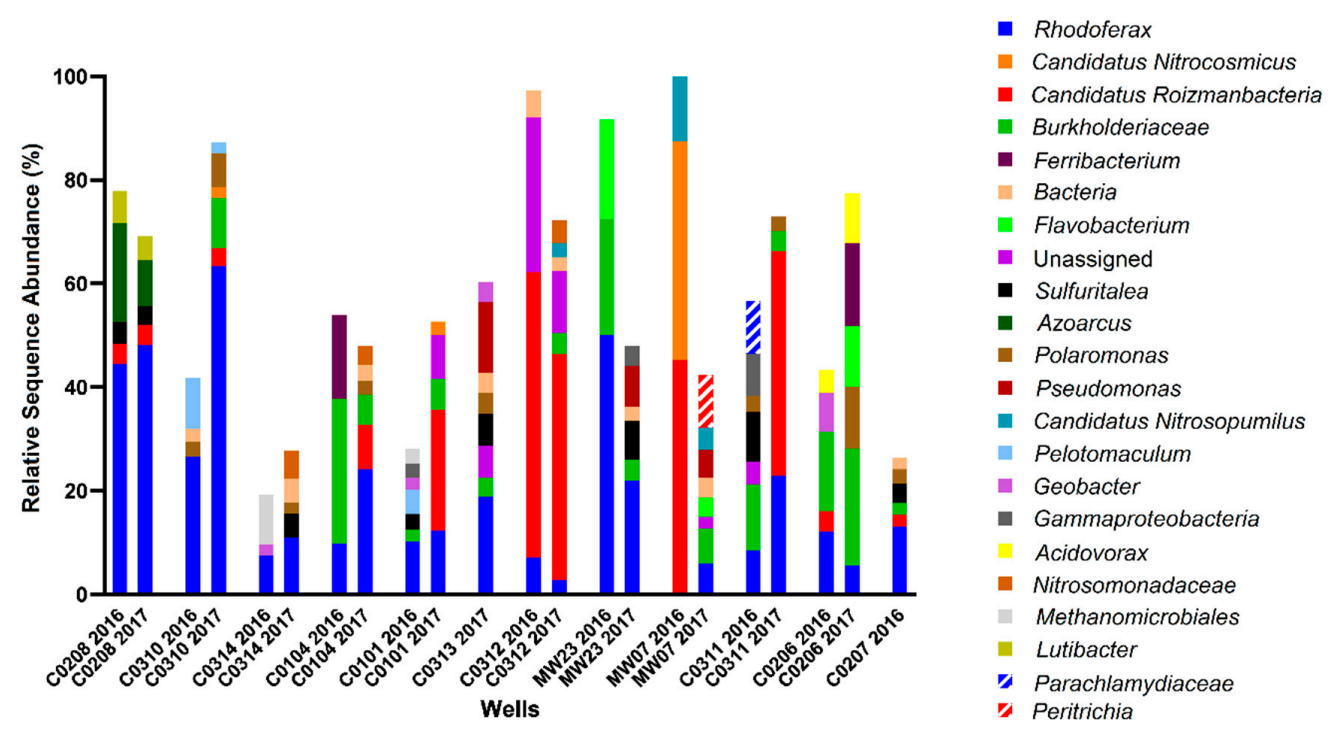

Figure 3. Microbial community profiles found with Site A groundwater wells in 2016 and 2017, with wells arranged in order of decreasing total hydrocarbon concentration, from left to right. Analysis was performed using MetaAmp 2.0 and the SILVA 132 database, with the $2 \%$ most abundant taxa shown to the lowest taxonomic level identified.
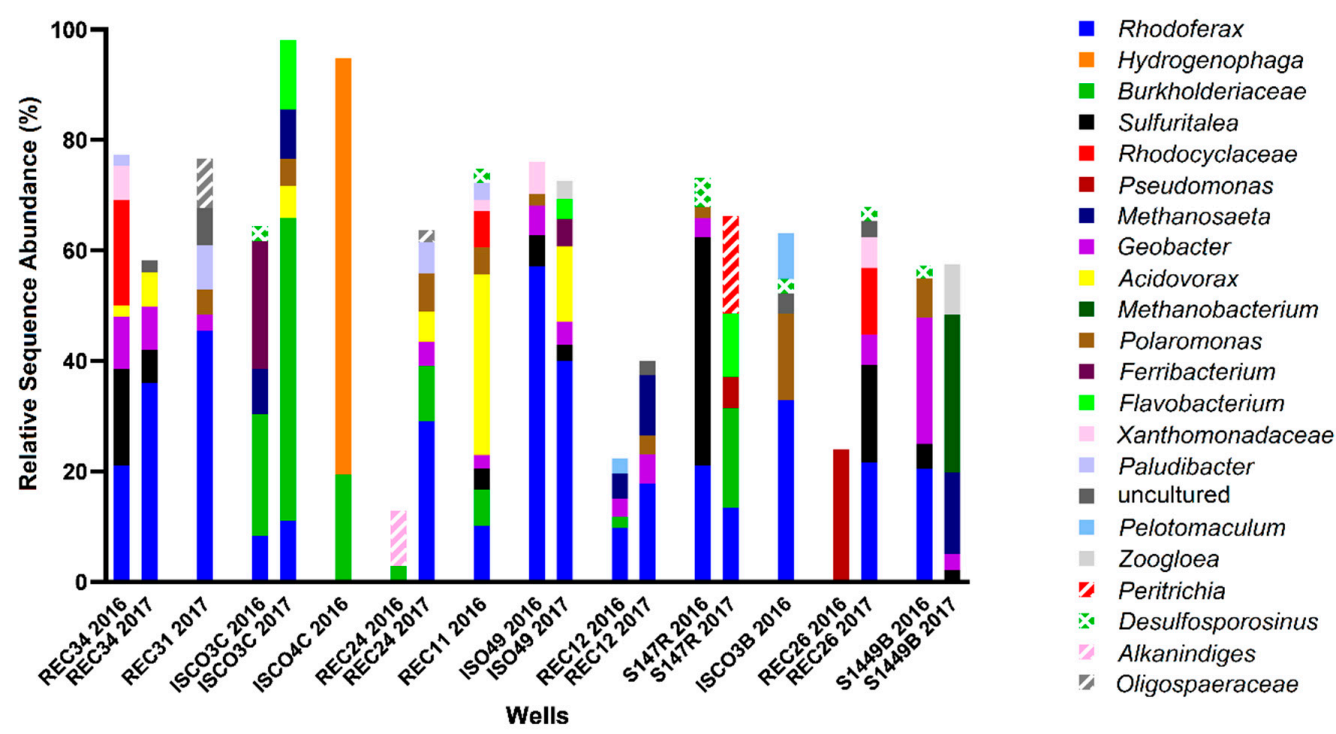

Figure 4. Microbial community profiles found with Site B groundwater wells in 2016 and 2017, with wells arranged in order of decreasing total hydrocarbon concentration, from left to right. Analysis was performed using MetaAmp 2.0 and the SILVA 132 database, with the $2 \%$ most abundant taxa shown to the lowest taxonomic level identified. 


\subsection{Fumarate Addition Metabolites and Biodegradation Genes}

While microbial community profiling results and biogeochemical measurements revealed the presence of some putative hydrocarbon degraders and anaerobic electron acceptors at Sites A and B, heterogeneity at these sites precluded definitive evidence supporting in situ anaerobic hydrocarbon biodegradation. Therefore, additional evidence was sought based on diagnostic fumarate metabolites and genes across each site.

\subsubsection{Alkylsuccinates and ass $A$ Genes}

Table 2 overviews the detection of alkylsuccinates and the ass $A$ gene at sampled locations across both Sites A and B. Measured alkane concentrations in each well are also indicated on Table 2. Alkylsuccinates that originated from the anaerobic biodegradation of $\mathrm{C}_{5}$ to $\mathrm{C}_{9}$ alkanes were detected at Site A, generally correlating with the qualitative detection of the ass $A$ gene (Table 2). One exception was for well C01-01, where the ass $A$ gene was not detected in the 2017 samples despite the detection of alkylsuccinates. In all sampled wells, alkylsuccinates were detected when the $C_{6}-C_{10}$ alkane concentrations were $0.1 \mathrm{ppm}$ or greater. While neither the ass $A$ gene nor alkylsuccinates were detected in the majority of the non-contaminated wells (wherein alkanes were below the detection limit of $<0.1 \mathrm{ppm}$ ), two anomalies were observed (Table 2). Two alkylsuccinates were detected in non-contaminated well C03-11 in both 2016 and 2017, although no ass $A$ genes could be qualitatively detected; for this well, it is possible that groundwater flow transported alkylsuccinates produced elsewhere in aquifer into the vicinity of the groundwater well. The ass $A$ gene was detected in well C02-07 in the 2016 sampling event, although corresponding metabolites were not found.

At Site B, fumarate addition metabolites derived from alkanes were detected in 10 of the 12 wells sampled (Table 2). The alkylsuccinates identified were primarily derived from $C_{5}$ to $C_{7}$ linear or cyclic alkanes. As with the results from Site A, a co-occurrence of alkylsuccinates and the ass $A$ gene (as determined qualitatively) was observed for the majority of the sample wells at Site B, with a few exceptions. Some groundwater samples revealed the presence of the ass $A$ gene, but not the corresponding alkylsuccinates (ISO-49 in 2016, REC 12 in 2017, REC 26 in 2016 and 2017). Alkylsuccinates nor the ass $A$ gene could be qualitatively detected at the lone non-contaminated well sampled at Site B, well S14-49B (Table 2). Despite the lack of universal co-occurrence of alkylsuccinates and the ass $A$ gene, the results on balance offer strong evidence that the microbial communities indigenous to the groundwater at both Sites A and B are capable of in situ anaerobic alkane biodegradation.

In addition to the presence/absence analysis of the ass $A$ gene based on PCR, we also quantified ass $A$ gene abundances using a mixture of newly designed qPCR primers (Figure 5, Table 2). Using these qPCR primers, the ass $A$ gene (verified by Sanger sequencing) was detected in 9 of the 12 wells at Site A (Figure 5A). At Site A, qPCR analyses showed that ass A gene abundances increased from $\log$ 5-6 copies/L in non-contaminated groundwater wells to $\log 7-8$ copies/L in wells with measurable alkane concentrations. Quantification of the ass $A$ gene showed that the highest alkane-contaminated wells, C02-08 (5.5 ppm total alkanes) and C03-14 (4.4 ppm total alkanes) had ass $A$ abundances of $10^{7}$ copies/L and $10^{8}$ copies/L, respectively. The qPCR primer mixture revealed between $10^{5}$ and $10^{6} \mathrm{copies} / \mathrm{L}$ in three of the five wells with non-detectable alkane concentrations (wells C02-07, C03-11, and MW-07). In general, increased abundances of the ass $A$ gene positively correlated with increased alkane concentrations at Site A (Figure 5A). 
Table 2. Detection of alkane/cyclic alkane-derived fumarate addition metabolites and ass $A$ genes (qualitatively and quantitatively determined) in Site A and B groundwater wells sampled in 2016 and 2017. "2016" or "2017" indicates that the metabolite was detected in that year, while "ass A" denotes gene detection. A blank space denotes absence of metabolite or gene.

\begin{tabular}{|c|c|c|c|c|c|c|c|c|c|c|c|c|c|c|c|c|}
\hline & \multirow[b]{2}{*}{ Well } & \multirow{2}{*}{$\begin{array}{c}\text { Alkanes } \\
\begin{array}{c}\text { C6-C10 } \\
\text { Alkanes } \\
(\mathrm{ppm})\end{array}\end{array}$} & \multicolumn{10}{|c|}{ Detected Alkylsuccinates } & \multicolumn{2}{|c|}{$\begin{array}{l}\text { assA Gene } \\
\text { Presence }\end{array}$} & \multicolumn{2}{|c|}{$\begin{array}{l}\text { assA Gene Abundance } \\
\text { (copies/L GW) }^{5}\end{array}$} \\
\hline & & & C5 & C5 unsat $^{1}$ & C6 & C6 unsat & C7 & C7 unsat & $\mathrm{C} 8$ & C8 unsat & C9 & C9 unsat & 2016 & 2017 & 2016 & 2017 \\
\hline & C02-08 & 5.5 & & 2016 & & 2016 & 2017 & & 2016/2017 & 2016 & 2016 & & ass $A$ & ass $A$ & $1.09 \times 10^{7}$ & $1.17 \times 10^{7}$ \\
\hline & $\mathrm{C} 03-14$ & 4.4 & & & & 2016 & & 2016/2017 & & 2016 & & 2016 & ass $A$ & ass $A$ & $2.43 \times 10^{8}$ & $2.86 \times 10^{8}$ \\
\hline & $\mathrm{C} 03-10$ & 0.9 & 2016/2017 & 2016 & & 2016/2017 & & 2016/2017 & & 2016/2017 & & 2017 & ass $A$ & ass $A$ & $1.57 \times 10^{7}$ & $2.45 \times 10^{7}$ \\
\hline & C01-04 & 0.5 & 2016/2017 & & & 2016/2017 & & 2016/2017 & & 2016 & & & ass $A$ & ass $A$ & & \\
\hline & $\mathrm{C} 03-13^{3}$ & 0.4 & & & & & 2017 & & 2017 & & & 2017 & & ass $A$ & - & $4.64 \times 10^{6}$ \\
\hline & C01-01 & 0.2 & & & & 2016 & 2016/2017 & & 2016/2017 & $2016 / 2017$ & 2016/2017 & 2016/2017 & ass $A$ & & $3.15 \times 10^{7}$ & \\
\hline & C03-12 & 0.1 & & & & & & 2016 & & 2016 & & 2017 & ass $A$ & ass $A$ & $3.81 \times 10^{5}$ & $1.45 \times 10^{6}$ \\
\hline & $\mathrm{C} 02-06$ & $<0.1^{2}$ & & & & & & & & & & & & & & \\
\hline & $\mathrm{C} 02-07$ & $<0.1$ & & & & & & & & & & & ass $A$ & & $3.27 \times 10^{6}$ & \\
\hline & C03-11 & $<0.1$ & & & & 2016/2017 & & $2016 / 2017$ & & & & & & & $2.25 \times 10^{6}$ & $4.34 \times 10^{5}$ \\
\hline & MW 07 & $<0.1$ & & & & & & & & & & & & & $1.86 \times 10^{5}$ & $2.72 \times 10^{5}$ \\
\hline & MW23 & $<0.1$ & & & & & & & & & & & & & & \\
\hline & $\begin{array}{c}\text { TRIP } \\
\text { BLANK }\end{array}$ & $<0.1$ & & & & & & & & & & & & & & \\
\hline \multirow{5}{*}{$\begin{array}{l}\text { Site } \\
\text { A }\end{array}$} & REC-34 & 9.9 & $2016 / 2017$ & $2016 / 2017$ & & $2016 / 2017$ & & 2016 & & & & & $a s s A$ & $a s s A$ & $1.15 \times 10^{7}$ & $1.08 \times 10^{6}$ \\
\hline & REC-31 & 5.5 & 2017 & $2016 / 2017$ & & $2016 / 2017$ & & 2016/2017 & & & & & & $a s s A$ & & $6.61 \times 10^{7}$ \\
\hline & ISCO-03-C & 3.1 & 2016 & 2016 & & 2016 & & & & & & 2016 & ass $A$ & ass $A$ & & \\
\hline & ISCO-04-C ${ }^{4}$ & 2.8 & 2016 & 2016 & & 2016 & & & & & & & ass $A$ & & $2.61 \times 10^{6}$ & - \\
\hline & REC-24 & 2.8 & $2016 / 2017$ & $2016 / 2017$ & & $2016 / 2017$ & & & & & & & ass $A$ & ass $A$ & & $1.69 \times 10^{7}$ \\
\hline \multirow{8}{*}{$\begin{array}{c}\text { Site } \\
\text { B }\end{array}$} & REC-11 ${ }^{4}$ & 2.7 & 2016 & 2016 & & & & & & & & & ass $A$ & & $2.21 \times 10^{7}$ & - \\
\hline & REC-12 & 2.2 & 2016 & & & & 2016 & & & & & & ass $A$ & ass $A$ & $3.00 \times 10^{7}$ & $1.34 \times 10^{7}$ \\
\hline & ISO-49 & 1.3 & 2017 & & 2017 & 2017 & & 2017 & & & & & ass $A$ & $\operatorname{ass} A$ & $1.76 \times 10^{7}$ & $1.03 \times 10^{7}$ \\
\hline & S14-7R & 1.2 & $2016 / 2017$ & 2016/2017 & & $2016 / 2017$ & & 2017 & & & & & ass $A$ & ass A & $3.44 \times 10^{6}$ & $9.80 \times 10^{7}$ \\
\hline & REC-26 & 0.2 & & & & & & & & & & & ass $A$ & ass $A$ & $3.02 \times 10^{9}$ & $1.45 \times 10^{9}$ \\
\hline & ISCO-03-B 4 & $<0.1$ & & & & 2016 & & & & & & & ass $A$ & & $4.64 \times 10^{6}$ & - \\
\hline & S14-49B & $<0.1$ & & & & & & & & & & & & & $1.36 \times 10^{6}$ & $1.42 \times 10^{6}$ \\
\hline & Trip Blank & $<0.1$ & & & & & & & & & & & & & & \\
\hline
\end{tabular}

${ }^{1}$ unsat indicates a fumarate addition product with 2 mass units less that an $n$-alkane, presumably derived from the metabolism of a cyclic alkane; ${ }^{2}$ below the analytical detection limit of

$0.1 \mathrm{ppm} ;{ }^{3}$ well not sampled in 2016; ${ }^{4}$ well not sampled in 2017; ${ }^{5}$ A dash indicates that no quantification was performed as no sample was received that year. A blank space indicates that

the gene could not be detected or quantified using the quantitative polymerase chain reaction (qPCR) primer set. 
Quantification of the ass $A$ gene in Site B samples showed a range of almost 4 orders of magnitude difference across the site (Figure 5B). Well S14-49B, the sole uncontaminated well, harboured $10^{6} \mathrm{copies} / \mathrm{L}$ of the ass $A$ gene, the lowest abundance measured at Site B. Of the 16 wells (both years) from which ass $A$ could be quantified, nine harboured $10^{7}$ copies/L, spanning alkane concentrations from approximately 2 ppm (REC 12) to $10 \mathrm{ppm}$ (REC 34, 2016 sample only) (Figure 5B). However, the highest ass $A$ gene abundance of $10^{9}$ copies/L was found in well REC 26, where only 0.2 ppm alkanes were measured. In contrast, REC 34, the groundwater well having the highest measured alkane concentration of all the sampled wells ( 10 ppm), had $10^{6}$ and $10^{7}$ ass $A$ gene copies/L, differing in an order of magnitude between sampling years (Figure $5 \mathrm{~B}$ ). The majority of the wells sampled at Site B harboured between $5 \times 10^{6}$ and $10^{8}$ ass $A$ gene copies/L, with only a single well harbouring $10^{9}$ copies/L. At Site B, the ass $A$ gene abundance appears to increase with increasing alkane concentrations up to a limit of approximately $5 \mathrm{ppm}$ alkanes; after this concentration, this trend is no longer seen. Additional samples with $>5$ ppm alkanes would be needed to verify this observation (Figure $5 \mathrm{~B}$ ).
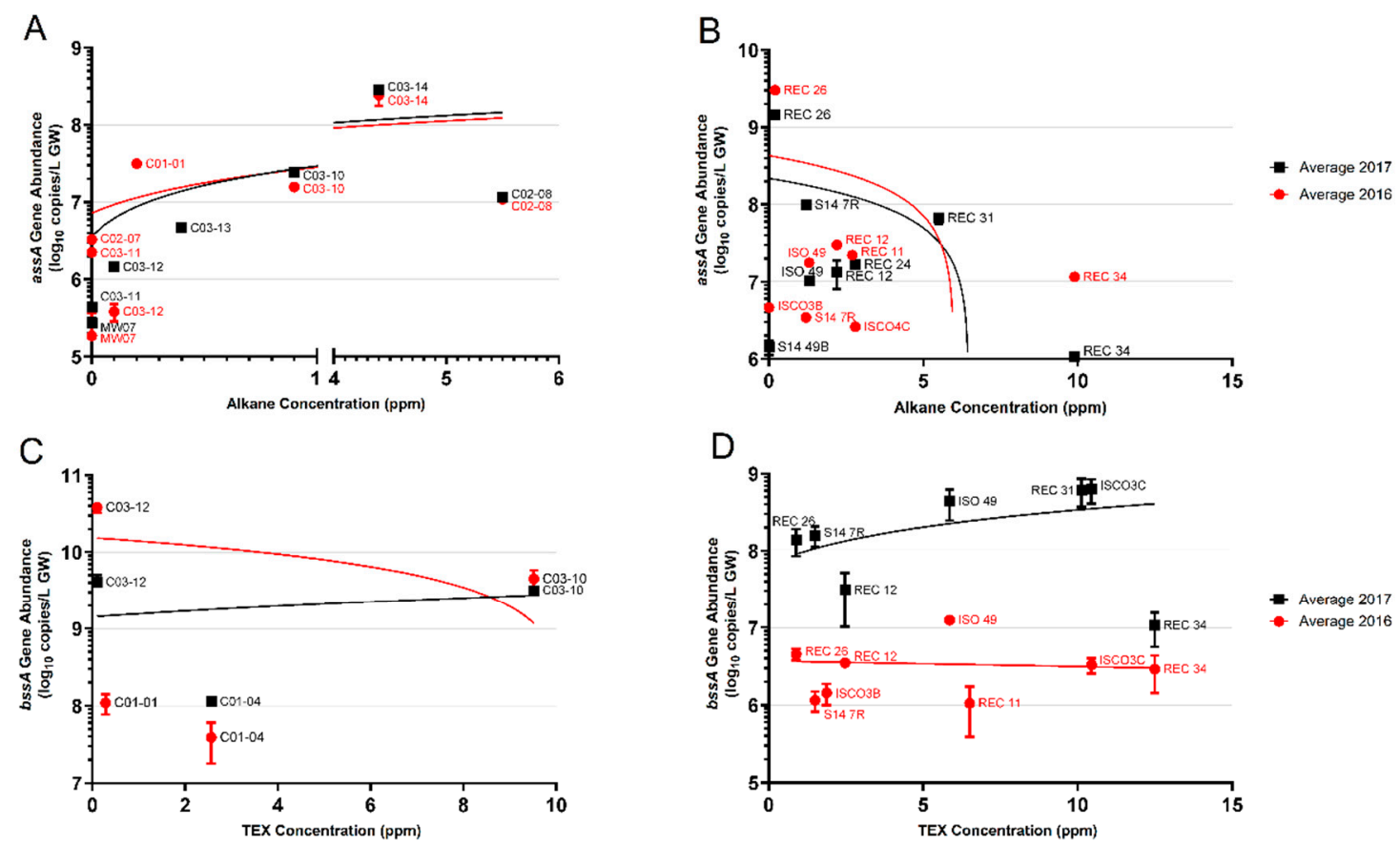

Figure 5. Quantifications of the ass $A$ and $b s s A$ genes in Sites A and B across 2 years (2016, red circles; 2017, black squares), plotted as a function of alkane or TEX (toluene, ethylbenzene, and xylene) concentrations, respectively. (A) ass A gene abundances in Site A wells; (B) ass A gene abundances in Site B wells; (C) bssA gene abundances in Site A wells; (D) bssA gene abundances in Site B wells. Linear regression trend lines are matched in colour. Only those samples whose amplicons matched the length of standard amplicons are plotted. Error bars represent the standard deviation of technical replicates $(n=3)$.

\subsubsection{Benzylsuccinates and $b s s A$ Genes}

Table 3 summarizes the fumarate addition metabolites and bss $A$ genes detected from Sites A and B. The frequency of benzylsuccinate (or an alkylated analog) detection in all sampled wells was comparatively lower than for alkylsuccinates for both sites (Table 2). For site A, methylbenzylsuccinates were detected only in the two most highly contaminated wells (C02-08 and C03-14). For well C02-08, the metabolites and $b s s A$ gene (qualitative detection) co-occurred, while this was only the case in 2017 from well C03-14 (Table 2). Fumarate addition metabolites derived from alkylbenzenes were not detected in any other samples from this site, although $b s s A$ was present almost universally, including in the samples wherein alkylbenzenes were below detection. 
Table 3. Detection of TEX-derived fumarate addition metabolites and $b s s A$ genes (qualitatively and quantitatively determined) in Site A and B groundwater wells sampled in 2016 and 2017. "2016" or "2017" indicates that the metabolite was detected in that year, while "bssA" denotes gene detection. A blank space denotes absence of metabolite or gene.

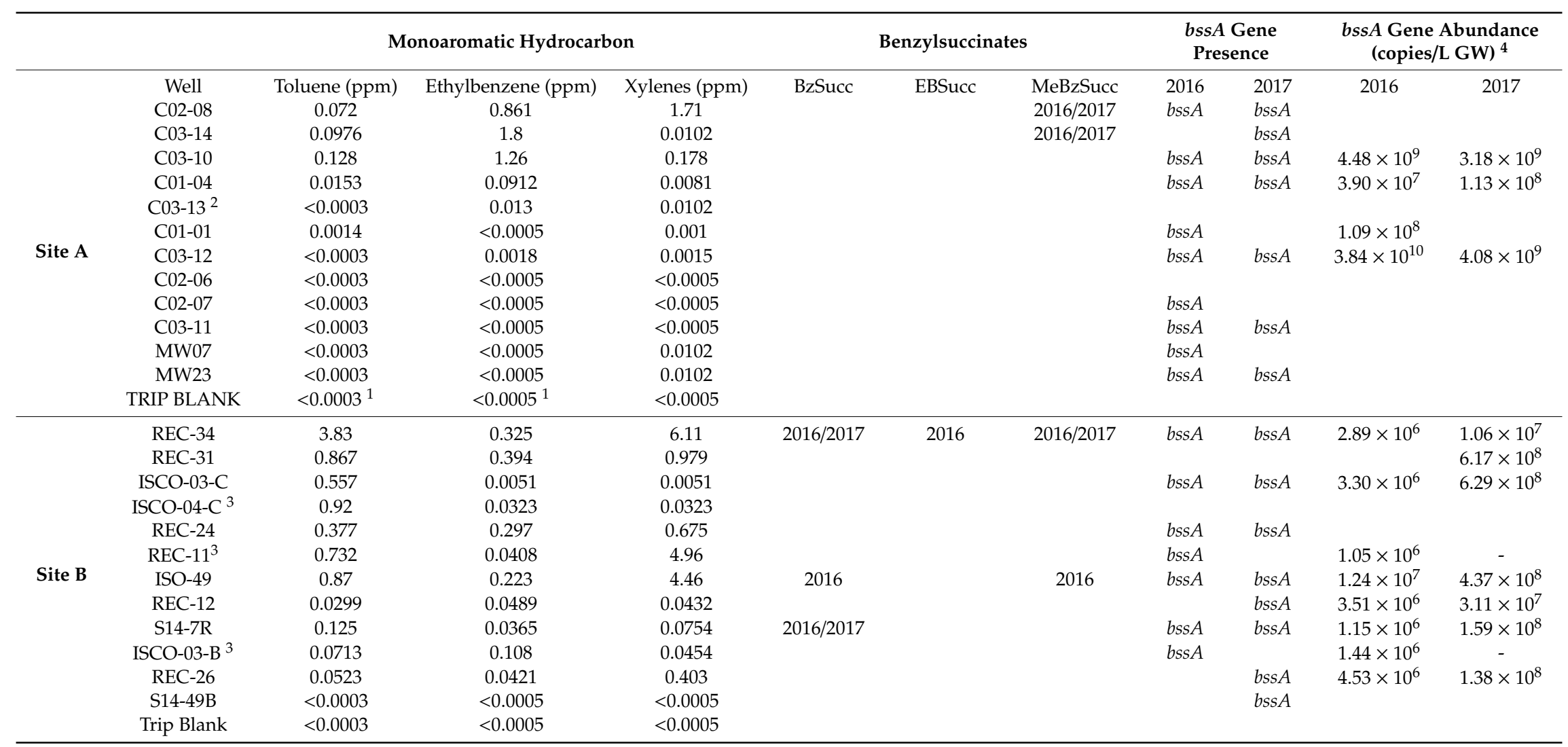

${ }^{1}$ below the analytical detection limit of $0.0003 \mathrm{ppm}$ for toluene and $0.0005 \mathrm{ppm}$ for ethylbenzene or xylenes; ${ }^{2}$ well not sampled in $2016 ;{ }^{3}$ well not sampled in $2017 ;{ }^{4} \mathrm{~A}$ dash indicates that no quantification was performed as no sample was received that year. A blank space indicates that the gene could not be detected or quantified using the qPCR primer set. 
A similar lack of alkyl aromatic metabolite detection was seen for Site B groundwater samples (Table 3). While a co-occurrence of benzylsuccinates and the bss A gene was evident in three samples (REC 34, ISO-49 in 2016, S14-7R in both years), this was not the case for the majority of the samples. Furthermore, for two contaminated groundwater samples at Site B (REC 31 and ISCO-04-C), neither a fumarate addition metabolite nor the $b s s A$ gene were detected using a qualitative approach (Table 3 ).

Figure 5C shows the quantification of the $b s s A$ gene plotted against TEX concentrations in Site A. False positives (those with non-specific amplicons) and zero value quantifications were not plotted. Only 4 wells had quantifiable $b s s A$ with the qPCR primers used. Wells C03-12 and C03-10 revealed the most abundant $b s s A$ per litre groundwater $\left(C 03-122016=10^{10}\right.$ copies $/ \mathrm{L}, 2017=10^{9} \mathrm{copies} / \mathrm{L}$; C03-10 2016 and $2017=10^{9}$ copies/L). With this limited data, there was no correlation between TEX concentration and bss A gene copies, as wells C03-12 and C03-10 harboured a similar bssA gene abundance, despite a 10-fold difference in TEX concentrations (Figure 5C, Table 3).

Quantification of the $b s s A$ gene in Site B samples plotted against TEX concentration shows that the minimum abundance of $b s s A$, regardless of TEX concentration, was approximately $1 \times 10^{6}$ copies/L (Figure 5D). Only one well, S14-7R, had tested positive in both 2016 and 2017, which saw a 138-fold increase in $b s s A$ copies/L from 2016 to 2017. As with Site A, there did not appear to be any correlation between TEX concentrations and quantities of the $b s s A$ gene; wells with similar TEX concentrations exhibited at least 2 orders of magnitude difference in $b s s A$ abundance. Overall, the quantification of the $b s s A$ gene in the two field sites suggests that $b s s A$ gene abundances are independent of aromatic hydrocarbon concentrations using the designed qPCR primers.

\section{3. assA and bssA Amplicon Sequencing Results}

Figure 6 shows the relationship of sequenced $\operatorname{ass} A$ and $\operatorname{bss} A$ amplicons present in the site groundwaters following amplification of these genes with the newly designed qPCR primers. After read preparation and quality control of amplicons, a BLASTn search of 86 sequences returned 6 that matched NCBI entries annotated as ass $A$ with $>70 \%$ identity and coverage. Clustering of the various sequences shows that 2 main clusters of ass $A$ sequences were present in these samples, all within the deltaproteobacteria; those that affiliated with sulfate-reducers (such as Desulfatibacillum alkenivorans, and Desulfatibacillum aliphaticivorans) and those affiliating with methanogenic/syntrophic cultures (with Smithella sp.) or oilfield-derived clones [19,22,46,47]. Some BLASTn results affiliated with the ass $A$ genes of the organisms from which the primers were designed. For example, primer 'assOri' was designed from D. alkenivorans, and primer 'assSml' was designed to capture Smithella SCADC sequences; sequences closely related to the ass $A$ genes from these taxa were found (Figure 6). The other primers in the primer mix, 'assMsd' and 'assEx' were designed from an annotated masD sequence and Desulfoglaeba alkenexedens, respectively. An ass A sequence similar to that of D. alkenexedens was detected in these samples. It is likely that the directed design of the primers in the primer mix influenced the types of ass $A$ sequences that resulted from the analysis. Many of the BLASTn matches were not annotated as ass $A$ yet had coverage and identity above $70 \%$. These were instead annotated to be involved in protein catabolism, ribosomes, or other metabolic functions (Table S4). Many of the organisms harbouring the sequence mismatches are known as aerobic/microaerophilic and are present in hydrocarbon-contaminated sites such as Variovorax (aerobic, aromatics), Polaromonas (aerobic, aromatics), Azoarcus (facultative, aromatic and alkane), Massilia (aerobic, PAH), and others [48-51]. This suggests that either the ass $A$ gene is present in these genomes but is currently uncharacterized, or non-specific binding is amplifying non-ass $A$ genes from these organisms, or many sequences annotated in silico may not be annotated as FAE genes. Notably, this non-specific binding explanation has an additional consequence of inflating gene abundances in quantification assays, which we cannot rule out here. Previous groups have not used next-generation sequencing platforms for their ass $A$ or bss $A$ identifications, and thus such non-specific binding has not been reported $[19,20,22,23,40]$. Future work that comprehensively examines the possible explanations for sequence mismatches (that includes additional sequences retrieved from other sites) is warranted. 


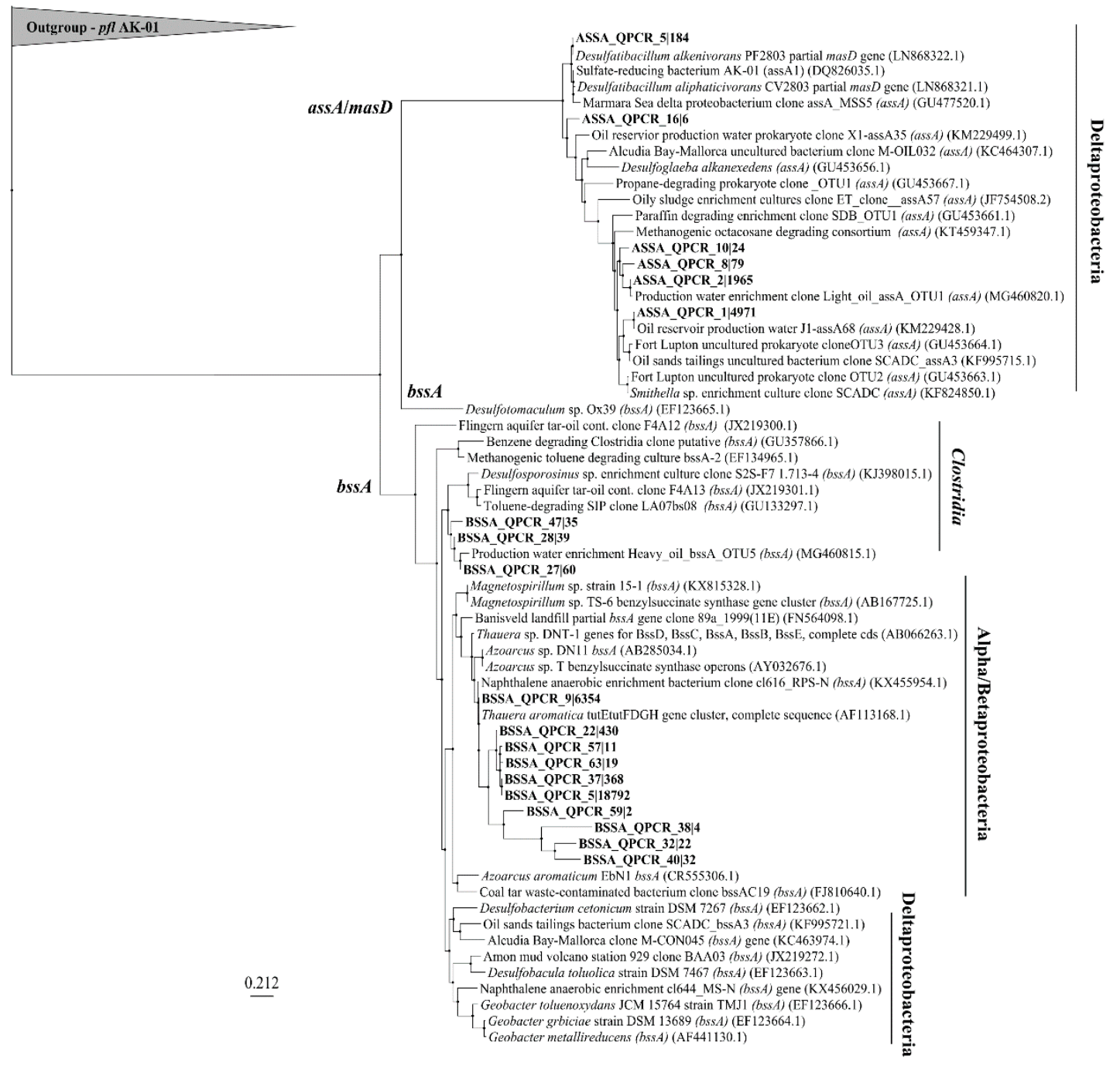

Figure 6. Maximum likelihood phylogram of sequenced ass $A$ and $b s s A$ amplicons. Nucleic acid sequences were aligned with ClustalX (30 iterations). Tree-building via PhyML 3.0 Maximum Likelihood using TN93 substitution model, fast likelihood-based method aLRT (approximate likelihood ratio test) for branch supporting, and SPR (subtree pruning and re-grafting) tree improvement model. The outgroup is pyruvate formate lyase (pfl) from sulfate-reducing strain D. alkenivorans strain AK-01.

For the $b s s A$ gene, a BLASTn search yielded 13 OTUs (operational taxonomic units) with matches to $b s s A$ sequences from 65 quality assessed sequences. A maximum likelihood analysis shows that 2 main clusters of bss $A$ formed, one clustering within the Clostridia, and the other clustering within the Alphaproteobacteria and Betaproteobacteria, such as Thauera (tut operon) [52], Azoarcus, and Magnetospirillum. No bss A sequences were retrieved from Deltaproteobacteria. The tut operon found in Thauera aromatica was also a dominant match in many of the sequences. Such clustering across betaproteobacterial species like Azoarcus and Thauera, suggests that these sequences are very similar, and are also similar to Magnetospirillum spp. bss $A$ sequences. Compared to non-specific matches using the ass $A$ primer mix, few bss $A$ non-matches were seen. These included matches to an acyl-CoA dehydrogenase (which is involved in $\beta$-oxidation of fatty acids), a $30 \mathrm{~S}$ rRNA gene (smaller subunit of prokaryotic ribosome), and surprisingly, an ass $A$ match.

\section{Discussion}

A multitude of approaches can be used to determine whether a hydrocarbon-contaminated groundwater site is undergoing bioremediation, each with advantages and limitations [25]. For example, 
measuring concentration differences of potential electron acceptors (such as $\mathrm{O}_{2}$, nitrate, sulfate) or respiration products (such as $\mathrm{CO}_{2}, \mathrm{Fe}(\mathrm{II})$, sulfide, $\mathrm{CH}_{4}$ ), or changes in microbial numbers and/or taxonomic compositions in contaminated areas versus uncontaminated areas can indicate microbial changes in response to hydrocarbon presence [25,26]. However, these measurements do not directly indicate that hydrocarbons are being biodegraded in situ. Compound-specific isotope analysis (CSIA) which measures isotopic changes in hydrocarbons themselves as they are being biotransformed, is a powerful approach for proving biodegradation, but isotopic fractionation can vary in heterogeneous sites and large isotopic changes are needed [25]. Similarly, identifying known hydrocarbon metabolites in hydrocarbon-contaminated groundwater provides direct evidence that the extant microorganisms are indeed biotransforming hydrocarbons in situ [5,27], but requires prior knowledge of such degradation pathways. Thus, coupling multiple approaches to assess sites for their bioremediation potential can help overcome methodological limitations. In this study, two hydrocarbon-contaminated groundwater sites, candidates for management by MNA, were interrogated using measurements of biogeochemical indicators, microbial community profiling, and diagnostic hydrocarbon metabolites and genes in order to garner evidence in support of in situ hydrocarbon biodegradation.

While biogeochemical measurements indicated that nitrate, sulfate, and/or Fe(III) reduction may be operating at both sites, no clear trends were seen that suggested any dominant electron accepting process occurring at either site. Similarly, microbial community profiling based on the $16 \mathrm{~S}$ rRNA gene indicated the presence of several anaerobic taxa and/or putative hydrocarbon-degraders, but taxonomic variation between all sampled groundwater wells precluded any clear conclusions that hydrocarbon-biodegrading taxa may have been stimulated in one site location versus another. Of note, both $\mathrm{H}_{2}$ - and acetate-using methanogens were also identified via 16S rRNA gene sequencing, with the highest relative sequence abundance found in the uncontaminated well sampled at Site B. Although $\mathrm{H}_{2}$ and acetate were not measured in this study, we can speculate that they were formed in uncontaminated groundwater during the decomposition of dissolved organic matter by syntrophic bacteria acting in concert with methanogens. Previous reports describing microbial communities and biogeochemical transformations in pristine groundwater have suggested such interactions stimulated by dissolved organic matter decomposition [53,54].

Fumarate addition metabolites known to originate from the anaerobic biodegradation of both alkanes and alkyl monoaromatics were detected at several locations at both sites. The corresponding diagnostic biodegradation genes, ass $A$ and $b s s A$, were also widely detected at both sites. Collectively, these results clearly demonstrated that both sites harbour anaerobic hydrocarbon-degrading microbial populations; as such, MNA could be a remedial option at these sites. Fumarate addition metabolites have been detected in many hydrocarbon-contaminated groundwater aquifers [5]. Most previous studies have focused on the identification of (methyl)benzylsuccinates originating from alkyl-substituted monoaromatic hydrocarbons, with fewer reports describing the detection of alkylsuccinates derived from alkanes in contaminated groundwater environments $[36,55,56]$. Refined fuel mixtures, such as the gasoline and diesel contaminants relevant to this study, are composed of low molecular weight alkanes and cyclic alkanes in addition to monoaromatic hydrocarbons. Thus, detecting fumarate addition metabolites from both classes of hydrocarbons is not unexpected in groundwater systems contaminated with such fuels $[36,55]$.

The $b s s A$ gene, encoding the FAE benzylsuccinate synthase, has also been sought and detected in numerous groundwater sites as an indicator of hydrocarbon biodegradation and bioremediation potential [19,21,22,29-32,57,58]. In contrast, the ass $A$ gene (encoding alkylsuccinate synthase) has rarely been used to interrogate hydrocarbon-contaminated groundwater environments [20], although it is being increasingly sought and detected in marine systems such as hydrocarbon seeps and sediments $[22,24,31,59]$. We also detected both of these genes in many of the groundwater sampling locations at both sites under study, augmenting the metabolite findings (Tables 2 and 3). With two exceptions (Site A, well C02-07 and Site B, well ISCO-03-B), the assA gene was detected only in wells also having detectable alkane concentrations (Table 2). In contrast, the $b s s A$ gene was detected 
in several wells having no detectable TEX concentrations (Table 3). Gittel et al. [23] detected ass A genes in both pristine and alkane-containing marine seep samples, suggesting the ubiquity of such genes and supporting the notion that pristine environments naturally harbor microorganisms capable of hydrocarbon metabolism when exposed to hydrocarbons. Such a hypothesis may pertain to terrestrial groundwater environments as well, in light of the findings in this present study and that by Brow et al. [60]. These latter authors reported bss $A$ transcripts on the order of $\log 4-5 / \mathrm{mL}$ in groundwater samples showing no detectable toluene, suggesting a basal/constitutive level of $b s s A$ expression in groundwater-associated microbial communities.

Although we observed a co-occurrence of both fumarate addition metabolites and relevant genes in many of the groundwater wells sampled for this study, this was not always the case. Alkylsuccinates were detected in parallel with qualitative ass $A$ gene detection in most wells (Table 2), although only one of these diagnostic indicators was detected in a small number of samples. The simultaneous detection of both (methyl)benzylsuccinate and the bss $A$ gene was much less pronounced than for the alkane degradation indicators. At Site A, only 2 of the 12 sampled wells showed the detection of both relevant metabolite and gene, only 3 of the 12 wells at Site B showed a co-occurrence of a (methyl)benzylsuccinate and the $b s s A$ gene. Such discrepancies were also noted in other studies that analyzed for both the $b s s A$ gene and related metabolites [30,32], where only one or the other diagnostic indicator was detected in many sampled wells. While the reasons for these disparities are not completely clear, some explanations can be considered. For example, the lack of detection of a given diagnostic metabolite in a contaminated groundwater system does not necessarily mean that the microbial community does not have the ability to biodegrade the parent hydrocarbon. As fumarate addition metabolites are metabolic intermediates, they may not accumulate to levels above that of the analytical detection limits, thus preventing their identification. Furthermore, as these metabolites have limited solubility at the low concentrations in which they may be detected (nM levels), it is also possible that they were transported in groundwater away from the location where they were initially produced and thus were not detected in the sampled locations. This may be especially true for benzylsuccinates which were not detected in the majority of the wells. However, because the relative aqueous solubilities of benzylsuccinates versus alkylsuccinates are not known, this explanation remains speculative. Similarly, metabolite assays as conducted here represent a 'snapshot' of the groundwater chemistry at the time of sampling [36,55], and thus the activity of the microbial community, along with dilution effects due to groundwater flow, can impact the positive detection of metabolites such as benzylsuccinates.

Similarly, the lack of detection of $b s s A$ or ass $A$, despite metabolite detection, may be due to limitations with the primer sets used for their amplification and detection. Both of these genes are known to be highly diverse, spanning multiple taxa and environments [22-24]. As such, no single primer pair designed to date has captured ass $A$ or $b s s A$ diversity comprehensively $[19,20,29,30]$. Such may be the case in the present study, where a single primer set designed for each gene was used for its qualitative detection.

Owing to the limitation in diversity capture, few primer sets have been designed for the quantification of $a s s A$ or $b s s A$ genes. Those that have been designed have a limited detection scope, either specific for sulfate-reducing or nitrate-reducing strains or for taxa in specific enrichments $[22,23,40,60,61]$. For example, widely used qPCR bss $A$ primers were designed exclusively from betaproteobacterial bss A sequences, namely from Thauera aromatica strains K172 and T1, and Azoarcus sp. strain T [61]. As such, the sequences from other phyla may not be detected, an acknowledged limitation [61]. Other primer sets were subsequently designed to target additional taxa such as sulfate-reducing members of the Deltaproteobacteria and Clostridia [19,22]. Stagars et al. [24] designed 4 fluorescence FISH (fluorescence in-situ hybridization) probes which would allow for quantification of different clusters of $a s s A$ sequences identified in their study examining this gene in marine environments, however the prevalence of non-specific probe annealing reinforced the difficulty in accurately detecting FAE genes. Using the qPCR primer set designed here and sequencing the resulting amplicons, we positively 
identified bssA genes affiliating with the Clostridia, Alphaproteobacteria, and Betaproteobacteria and assA genes associated with organisms in the Deltaproteobacteria.

The qPCR primers newly designed for this study used a mixture of 4 forward primers and 1 reverse primer for each of the ass $A$ and $b s s A$ genes (Table 1). To our knowledge, this primer mixture approach, designed to capture broad diversity (see Supplementary Materials), has not been previously attempted for $a s s A$ nor $b s s A$ gene quantification. Using the qPCR primer mixture, we obtained gene abundances approximately 2 orders of magnitude greater than any other gene abundance value reported by other groups (Table 4). Generally, in contaminated aquifers, the gene abundance of $b s s A$ genes has been found to be between $10^{3}$ to $10^{8}$ copies/g sediment or copies/L water (Table 4 ). The large difference in the abundances of the $b s s A$ gene, ranging across 5 orders of magnitude, may also be dependent upon experimental differences, such as the primers used, the type of sample, toluene degradation activity, and the extent to which BSS-harbouring microorganisms were enriched in laboratory cultures or groundwater environments. Studies relating the abundance of $b s s A$ to $16 \mathrm{~S}$ rRNA gene abundances found that while the $16 \mathrm{~S}$ rRNA gene abundances were relatively consistent, the abundances of the $b s s A$ genes varied across orders of magnitude [30]. Other groups have detected background abundances (e.g., in uncontaminated samples) of $b s s A$ to be approximately $10^{4} \mathrm{copies} / \mathrm{L}$, while the lowest abundance captured in this study was $10^{5}$ copies/L (Table 4). With this higher detection limit, we may not have adequately quantified the $b s s A$ gene, especially in the Site A samples where we were not able to quantify this gene in many samples even though it was detected using the qualitative PCR assay (Table 3). Based on the limited number of wells wherein the $b s s A$ gene was quantified, no relationships between the $b s s A$ gene abundances and TEX concentrations were discernible.

In comparison with the few reported ass $A$ quantification studies, the overall abundances are similar, up to $\sim 8 \log$ per unit sample in higher contaminated samples (Table 4 ). To our knowledge, very few studies have quantified ass $A$ gene abundances in environmental samples, much less than for bss $A$ (Table 4), thus it is not known how our results compare to other field sites. Further studies of ass $A$ gene abundances in contaminated groundwater environments are needed. In contrast to $b s s A$ and TEX concentrations, there did appear to be a relationship between ass $A$ gene abundances and alkane concentrations wherein ass $A$ levels increased as alkane concentrations increased, at least up to $5 \mathrm{ppm}$ alkanes. However, many more samples would need to be analyzed across many different sites to verify this trend.

The overall results using the newly designed qPCR primers for ass $A$ and $b s s A$ showed that they did capture a diversity of taxa within the Alphaproteobacteria, Betaproteobacteria, Deltaproteobacteria, and Clostridia, offering a proof-of-concept demonstration of a customized primer mix for quantifying FAE genes in a groundwater environment. These data suggest that the use of a primer mix to target specific diversity can work, if prior knowledge allows a directed and purposeful design. As additional ass $A$ and $b s s A$ gene sequences become available in databases, adding these to and/or further optimizing the primer mix should aid in improved amplification and quantification of these indicative biodegradation genes in hydrocarbon-associated environments. 
Table 4. Comparisons of approximate reported ass $A$ and $b s s A$ gene abundances reported in literature and in the present study. Note that abundances reported in this study are up to $2 \log$ greater than other studies, in both detection limit and in highest reported abundances.

\begin{tabular}{|c|c|c|c|c|c|}
\hline $\begin{array}{l}\text { Targeted FAE } \\
\text { Gene }\end{array}$ & $\begin{array}{l}\text { Reported Detection } \\
\text { Limit (copies/L or g) }\end{array}$ & $\begin{array}{l}\text { Highest Reported } \\
\text { Sample Abundance } \\
\text { (copies/L or g) }\end{array}$ & Targeted Electron-Accepting Conditions & Cited Primer Reference & Reference \\
\hline \multirow{3}{*}{ ass $A$} & $\sim \log 5$ & $\sim \log 9$ & Sulfate-reducers and methanogenic consortia & & This Study \\
\hline & not reported & $\sim \log 6$ & Methanogenic paraffin degrading consortium & & Oberding and Gieg [62] \\
\hline & $\sim \log 3$ & $\sim \log 8$ & Sulfate-reducers and methanogenic consortia & & Aitken et al. [40] \\
\hline \multirow{10}{*}{$b s s A$} & $\sim \log 5$ & $\sim \log 10$ & Nitrate- and sulfate-reducers & & This Study \\
\hline & $\sim \log 2$ & $\sim \log 8$ & Sulfate-reducers & Winderl et al. [29] & Pilloni et al. [63] \\
\hline & $\sim \log 4$ & $\sim \log 8$ & Nitrate- and sulfate-reducers & $\begin{array}{c}\text { Winderl et al. [19] } \\
\text { non-qPCR primers } \\
\text { 7772f/8546r }\end{array}$ & Müller et al. [64] \\
\hline & $\sim \log 4$ & $\sim \log 4$ & Sulfate-reducers and methanogenic consortia & Beller et al. [30] & Oka et al. [32] \\
\hline & $\sim \log 2$ & $\sim \log 3$ & Nitrate-reducers & Beller et al. [61] & Oka et al. [32] \\
\hline & $\sim \log 1$ & $\sim \log 8$ & Nitrate-reducers & Beller et al. [61] & Kazy et al. [57] \\
\hline & $\sim \log 3$ & $\sim \log 8$ & Sulfate-reducers & & Beller et al. [30] \\
\hline & $\sim \log 3$ & $\sim \log 7$ & Deltaproteobacterial "F1" & & Winderl et al. [29] \\
\hline & $\sim \log 2$ & $\sim \log 8$ & Nitrate-reducers & Beller et al. [61] & Da Silva and Alvarez [58] \\
\hline & $\sim \log 3$ & $\sim \log 8$ & Nitrate-reducers & & Beller et al. [61] \\
\hline
\end{tabular}




\section{Conclusions}

Analyses of two hydrocarbon-contaminated groundwater systems, focused on combining assays for signature metabolite detection and FAE gene detection and quantification, revealed that both sites investigated showed strong potential for management by MNA. Newly designed qPCR primer mixtures revealed up to $10^{9}$ ass $A$ gene copies/L and up to $10^{10}$ bss $A$ gene copies/L at the study sites. While previous studies have reported the quantification of the $b s s A$ gene in hydrocarbon-contaminated groundwater, this present study has now also demonstrated the detection and quantification of ass $A$ genes in groundwater systems. While both metabolites and genes indicative of in situ hydrocarbon biodegradation were detected in some of the wells investigated, this was not always the case, similar to previous reports [30,32]. Thus, assessing field sites for evidence of in situ anaerobic hydrocarbon biodegradation should minimally use both approaches (in addition to other site assessments) to overcome any limitations each method may have in order to demonstrate the potential for hydrocarbon-contaminated groundwater to be naturally remediated by microorganisms.

Supplementary Materials: The following are available online at http://www.mdpi.com/2076-2607/8/10/1532/s1: Supplementary Methods: Design of $a s s A$ and $b s s A$ primer mixture, Table S1: Total hydrocarbon concentrations in groundwater collected from various wells from Site A and Site B, Table S2: Sequences used in ass $A$ and $b s s A$ primer design with description and accession number from NCBI database, Table S3: Designed Illumina MiSeq adapter primers for $a s s A$ and $b s s A$ qPCR primers, Table $S 4$ : Examples of sequenced ass $A$ assay products that passed quality control analysis but that were not annotated as alkylsuccinate synthase genes using a BLASTn analysis.

Author Contributions: Conceptualization, L.M.G. and G.K.; Methodology, L.M.G. and G.K.; Investigation, G.K. and G.S.; Data Curation, L.M.G., G.K., and G.S.; Writing-Original Draft Preparation, G.K.; Writing-Review and Editing, L.M.G., G.K., and G.S.; Supervision, L.M.G.; Project Funding Acquisition, L.M.G. All authors have read and agreed to the published version of the manuscript.

Funding: This research was funded by an NSERC Engage grant in partnership with the United Farmers of Alberta Co-operative Ltd., and an NSERC Discovery grant, both awarded to L.M.G.

Acknowledgments: We gratefully acknowledge the United Farmers of Alberta Co-operative Ltd. for the samples used in this study, AGAT Laboratories for hydrocarbon analysis, and Nuno Fragoso for help in creating field site schematics.

Conflicts of Interest: The authors declare no conflict of interest.

\section{References}

1. Lynge, E.; Andersen, A.; Nilsson, R.; Barlow, L.; Pukkala, E.; Nordlinder, R.; Boffetta, P.; Grandjean, P.; Heikkilä, P.; Hörte, L.G.; et al. Risk of cancer and exposure to gasoline vapors. Am. J. Epidemiol. 1997, 145, 449-458. [PubMed]

2. Hilpert, M.; Mora, B.A.; Ni, J.; Rule, A.M.; Nachman, K.E. Hydrocarbon release during fuel storage and transfer at gas stations: Environmental and health effects. Curr. Environ. Health Rep. 2015, 2, 412-422.

3. Head, I.M.; Gray, N.D.; Larter, S.R. Life in the slow lane; biogeochemistry of biodegraded petroleum containing reservoirs and implications for energy recovery and carbon management. Front. Microbiol. 2014, 5, 566. [PubMed]

4. Lueders, T. The ecology of anaerobic degraders of BTEX hydrocarbons in aquifers. FEMS Microbiol. Ecol. 2017, 93, fiw220. [PubMed]

5. Gieg, L.M.; Toth, C.R.A. Signature metabolite analysis to determine in situ anaerobic hydrocarbon biodegradation. In Anaerobic Utilization of Hydrocarbons, Oils, and Lipids; Handbook of Hydrocarbon and Lipid Microbiology Book Series; Boll, M., Ed.; Springer: Cham, Switzerland, 2017; Volume 30, 30p.

6. Rabus, R.; Boll, M.; Heider, J.; Meckenstock, R.U.; Buckel, W.; Einsle, O.; Ermler, U.; Golding, B.T.; Gunsalus, R.P.; Kroneck, P.N.H.; et al. Anaerobic microbial degradation of hydrocarbons: From enzymatic reactions to the environment. J. Mol. Microbiol. Biotechnol. 2016, 26, 5-28. [PubMed]

7. Zhang, X.; Young, L.Y. Carboxylation as an initial reaction in the anaerobic metabolism of naphthalene and phenanthrene by sulfidogenic consortia. Appl. Environ. Microbiol. 1997, 63, 4759-4764.

8. Davidova, I.A.; Gieg, L.M.; Duncan, K.E.; Suflita, J.M. Anaerobic phenanthrene mineralization by a carboxylating sulfate-reducing bacterial enrichment. ISME J. 2007, 1, 436-442. [PubMed] 
9. Mouttaki, H.; Johannes, J.; Meckenstock, R.U. Identification of naphthalene carboxylase as a prototype for the anaerobic activation of non-substituted hydrocarbons. Environ. Microbiol. 2012, 14, 2770-2774.

10. Luo, F.; Gitiafroz, R.; Devine, C.E.; Gong, Y.; Hug, L.A.; Raskin, L.; Edwards, E.A. Metatranscriptome of an anaerobic benzene-degrading enrichment culture reveals involvement of carboxylation in benzene ring activation. Appl. Environ. Microbiol. 2014, 80, 4095-4107.

11. Callaghan, A.V. Enzymes involved in the anaerobic oxidation of $n$-alkanes: From methane to long chain alkanes. Front. Microbiol. 2016, 4, 89.

12. Biegert, T.; Fuchs, G.; Heider, J. Evidence that anaerobic oxidation of toluene in the denitrifying bacterium Thauera aromatica is initiated by formation of benzylsuccinate from toluene and fumarate. Eur. J. Biochem. 1996, 238, 661-668.

13. Heider, J.; Szaleniec, M.; Martins, B.M.; Seyhan, D.; Buckel, W.; Golding, B.T. Structure and function of benzylsuccinate synthase and related fumarate-adding glycyl radical enzymes. J. Mol. Microbiol. Biotechnol. 2016, 26, 29-44.

14. Achong, G.R.; Rodriguez, A.M.; Spormann, A.M. Benzylsuccinate synthase of Azoarcus sp. strain T: Cloning, sequencing, transcriptional organization, and its role in anaerobic toluene and $m$-xylene mineralization. J. Bacteriol. 2001, 183, 6763-6770.

15. Kniemeyer, O.; Fischer, T.; Wilkes, H.; Glockner, F.O.; Widdel, F. Anaerobic degradation of ethylbenzene by a new type of marine sulfate-reducing bacterium. Appl. Environ. Microbiol. 2003, 69, 760-768.

16. Callaghan, A.V.; Wawrik, B.; Ni Chadain, S.M.; Young, L.Y.; Zylstra, G.J. Anaerobic alkane-degrading strain AK-01 contains two alkylsuccinate synthase genes. Biochem. Biophys. Res. Commun. 2008, 3366, 142-148.

17. Grundmann, O.; Behrends, A.; Rabus, R.; Amann, J.; Halder, T.; Heider, J.; Widdel, F. Genes encoding the candidate enzyme for anaerobic activation of $n$-alkanes in the denitrifying bacterium, strain HxN1. Environ. Microbial. 2008, 10, 376-385.

18. Meckenstock, R.U.; Boll, M.; Mouttaki, H.; Koelschbach, J.S.; Cunha Tarouco, P.; Weyrauch, P.; Dong, X.; Himmelburg, A.M. Anaerobic degradation of benzene and polycyclic aromatic hydrocarbons. J. Mol. Microbiol. Biotechnol. 2016, 26, 92-118.

19. Winderl, C.; Schaefer, S.; Lueders, T. Detection of anaerobic toluene and hydrocarbon degraders in contaminated aquifers using benzylsuccinate synthase (bss A) genes as a functional marker. Environ. Microbiol. 2007, 9, 1035-1046.

20. Callaghan, A.V.; Davidova, I.A.; Savage-Ashlock, K.; Parisi, V.A.; Gieg, L.M.; Suflita, J.M.; Kukor, J.J.; Wawrik, B. Diversity of benyzl- and alkylsuccinate synthase genes in hydrocarbon-impacted environments and enrichment cultures. Environ. Sci. Technol. 2010, 44, 7287-7294.

21. Acosta-Gonzáles, A.; Rosselló-Móra, R.; Marqués, S. Diversity of benzylsuccinate synthase-like (bss A) genes in hydrocarbon-polluted marine sediments suggests substrate-depending clustering. Appl. Environ. Microbiol. 2013, 79, 3667-3676.

22. Von Netzer, F.; Pilloni, G.; Kleindienst, S.; Krüger, M.; Knittel, K.; Gründger, F.; Lueders, T. Enhanced gene detection assays for fumarate-adding enzymes allow uncovering of anaerobic hydrocarbon degraders in terrestrial and marine systems. Appl. Environ. Microbiol. 2013, 79, 543-552.

23. Gittel, A.; Donhauser, J.; Roy, H.; Girguis, P.R.; Jorgensen, B.B.; Kjeldsen, K.U. Ubiquitous presence and novel diversity of anaerobic alkane degraders in cold marine sediments. Front. Microbiol. 2015, 6, 1414. [PubMed]

24. Stagars, M.H.; Ruff, S.E.; Amann, R.; Knittel, K. High diversity of anaerobic alkane-degrading microbial communities in marine seep sediments based on (1-methylalkyl)succinate synthase genes. Front. Microbiol. 2016, 6, 1511.

25. Bombach, P.; Richnow, H.H.; Kästner, M.; Fischer, A. Current approaches for the assessment of in situ biodegradation. Appl. Microbiol. Biotechnol. 2010, 86, 839-852. [PubMed]

26. Gieg, L.M.; Kolhatkar, R.V.; McInerney, M.J.; Tanner, R.S.; Harris, S.H., Jr.; Sublette, K.; Sulfita, J.M. Intrinsic bioremedation of petroleum hydrocarbons in a gas condensate-contaminated groundwater. Environ. Sci. Technol. 1999, 33, 2550-2560.

27. Beller, H.R.; Ding, W.H.; Reinhard, M. By-products of anaerobic alkylbenzene metabolism useful as indicators of in-situ bioremediation. Environ. Sci. Technol. 1995, 29, 2864-2870.

28. Jobelius, C.; Ruth, B.; Griebler, C.; Meckenstock, R.U.; Hollender, J.; Reineke, A.; Frimmel, F.H.; Zwiener, C. Metabolites indicate hot spots of biodegradation and biogeochemical monitoring well gradients in a high-resolution monitoring well. Environ. Sci. Technol. 2011, 45, 474-481. 
29. Winderl, C.; Anneser, B.; Griebler, C.; Meckenstock, R.U.; Lueders, T. Depth-resolved quantification of anaerobic toluene degraders and aquifer microbial community patterns in distinct redox zones of a tar oil contaminant plume. Appl. Environ. Microbiol. 2008, 74, 792-801.

30. Beller, H.R.; Kane, S.R.; Legler, T.C.; McKelvie, J.R.; Sherwood Lollar, B.; Pearson, F.; Balser, L.; Mackay, D.M. Comparative assessments of benzene, toluene, and xylene natural attenuation by quantitative polymerase chain reaction analysis of a catabolic gene, signature metabolites, and compound-specific isotope analysis. Environ. Sci. Technol. 2008, 42, 6065-6072.

31. Johnson, J.M.; Wawrik, B.; Isom, C.; Boling, B.; Callaghan, A.V. Interrogation of Chesapeake Bay sediment microbial communities for intrinsic alkane-utilizing potential under anaerobic conditions. FEMS Microbiol. Ecol. 2015, 91, 1-14. [PubMed]

32. Oka, A.R.; Phelps, C.D.; Zhu, X.; Saber, D.L.; Young, L.Y. Dual biomarkers of anaerobic hydrocarbon degradation in historically contaminated groundwater. Environ. Sci. Technol. 2011, 45, 3407-3414.

33. Okpala, G.N.; Chen, C.; Fida, T.; Voordouw, G. Effect of thermophilic nitrate reduction on sulfide production in high temperature oil reservoir samples. Front. Microbiol. 2017, 8, 1573.

34. Lovley, D.R.; Phillips, E.J.P. Rapid assay for microbially reducible ferric iron in aquatic sediments. Appl. Environ. Microbiol. 1987, 53, 1536-1540. [PubMed]

35. Toth, C.R.A.; Gieg, L.M. Time-course dependent methanogenic crude oil biodegradation: Dynamics of fumarate addition metabolites, biodegradative genes, and microbial community composition. Front. Microbiol. 2018, 8, 2610. [PubMed]

36. Gieg, L.M.; Suflita, J.M. Detection of anaerobic metabolites of saturated and aromatic hydrocarbons in petroleum-contaminated aquifers. Environ. Sci. Technol. 2002, 36, 3755-3762. [CrossRef]

37. An, D.; Caffrey, S.M.; Soh, J.; Agrawal, A.; Brown, D.C.; Budwill, K.; Dong, X.; Dunfield, P.F.; Foght, J.; Gieg, L.M.; et al. Metagenomics of hydrocarbon resource environments indicates aerobic taxa and genes to be unexpectedly common. Environ. Sci. Technol. 2013, 47, 10708-10717.

38. Zhang, J.; Kobert, K.; Flouri, T.; Stamatakis, A. PEAR: A fast and accurate Illumina Paired-End reAd merger. Bioinformatics 2014, 30, 614-620.

39. Dong, X.; Kleiner, M.; Sharp, C.E.; Thorson, E.; Li, C.; Liu, D.; Strous, M. Fast and simple analysis of MiSeq amplicon sequencing data with MetaAmp. Front. Microbiol. 2017, 8, 1461. [PubMed]

40. Aitken, C.M.; Jones, D.M.; Maguire, M.J.; Gray, N.D.; Sherry, A.; Bowler, B.F.J.; Ditchfield, A.K.; Larter, S.R.; Head, I.M. Evidence that crude oil alkane activation proceeds by different mechanisms under sulfate-reducing and methanogenic conditions. Geochim. Cosmochim. Acta 2013, 109, 162-174.

41. Altschul, S.F.; Madden, T.L.; Schäffer, A.A.; Zhang, J.; Zhang, Z.; Miller, W.; Lipman, D.J. Gapped BLAST and PSI-BLAST: A new generation of protein database search programs. Nucleic Acids Res. 1997, 25, 3389-3402.

42. Thompson, J.D.; Higgins, D.G.; Gibson, T.J. CLUSTALW: Improving the sensitivity of progressive multiple sequence alignment through sequence weighting, position-specific gap penalties and weight matrix choice. Nucleic Acids Res. 1994, 22, 4673-4680.

43. Guindon, S.; Dufayard, J.F.; Lefort, V.; Anisimova, M.; Hordijk, W.; Gascuel, O. New algorithms and methods to estimate maximum-likelihood phylogenies: Assessing the performance of PhyML 3.0. Syst. Biol. 2010, 59, 307-321. [PubMed]

44. Hordijk, W.; Gascuel, O. Improving the efficiency of SPR moves in phylogenetic tree search methods based on maximum likelihood. Bioinformatics 2005, 21, 4338-4347. [PubMed]

45. Alberta Environment and Parks (AEP). Alberta Tier 1 Soil and Groundwater Remediation Guidelines; Land Policy Branch, Policy and Planning Division: Edmonton, AB, Canada, 2019.

46. Cravo-Laureau, C.; Grossi, V.; Raphel, D.; Matheron, R.; Hirschler-Réa, A. Anaerobic n-alkane metabolism by a Desulfatibacillum aliphaticivorans strain CV2803 T. Appl. Environ. Microbiol. 2005, 71, 3458-3467.

47. Cravo-Laureau, C.; Matheron, R.; Cayol, J.L.; Joulian, C.; Hirschler-Réa, A. Desulfatibacillum aliphaticivorans gen. nov., sp. nov., an $n$-alkane- and $n$-alkene-degrading, sulfate-reducing bacterium. Int. J. Syst. Evol. Microbiol. 2004, 54, 77-83. [PubMed]

48. Jeon, C.O.; Park, W.; Ghiorse, W.C.; Madsen, E.L. Polaromonas naphthalenivorans sp. nov., a naphthalenedegrading bacterium from naphthalene-contaminated sediment. Int. J. Syst. Evol. Microbiol. 2004, 54, 93-97.

49. Sun, W.; Xie, S.; Luo, C.; Cupples, A.M. Direct link between toluene degradation in contaminated-site microcosms and a Polaromonas strain. Appl. Environ. Microbiol. 2010, 76, 956-959. 
50. Ehrenreich, P.; Behrends, A.; Harder, J.; Widdel, F. Anaerobic oxidation of alkanes by newly isolated denitrifying bacteria. Arch. Microbiol. 2000, 173, 58-64. [PubMed]

51. Iffis, B.; St-Arnaud, M.; Hijri, M. Bacteria associated with arbuscular mycorrhizal fungi within roots of plants growing in a soil highly contaminated with aliphatic and aromatic petroleum hydrocarbons. FEMS Microbiol. Lett. 2014, 358, 44-54.

52. Coschigano, P.W. Transcriptional analysis of the tutE tutFDGH gene cluster from Thauera aromatica strain T1. Appl. Environ. Microbiol. 2000, 66, 1147-1151.

53. Flynne, T.M.; Sanford, R.A.; Ryu, H.; Bethke, C.M.; Levine, A.D.; Ashbolt, N.J.; Santo Domingo, J.W. Functional microbial diversity explains groundwater chemistry in a pristine aquifer. BMC Microbiol. 2013, 13, 146.

54. Benk, S.A.; Yan, L.; Lehmann, R.; Roth, V.-N.; Schwab, V.F.; Totsche, K.U.; Küsel, K.; Gleixner, G. Fueling diversity in the subsurface: Composition and age of dissolved organic matter in the critical zone. Front. Earth Sci. 2019, 7, 296.

55. Parisi, V.A.; Brubaker, G.R.; Zenker, M.J.; Prince, R.C.; Gieg, L.M.; da Silva, M.L.B.; Alvarez, P.J.J.; Suflita, J.M. Field metabolomics and laboratory assessments of anaerobic intrinsic bioremediation of hydrocarbons at a petroleum-contaminated site. Microb. Biotechnol. 2009, 2, 202-212. [PubMed]

56. Agrawal, A.; Gieg, L.M. In situ detection of anaerobic alkane metabolites in subsurface environments. Front. Microbiol. 2013, 4, 140.

57. Kazy, S.K.; Monier, A.L.; Alvarez, P.J.J. Assessing the correlation between anaerobic toluene degradation activity and $b s s A$ concentrations in hydrocarbon-contaminated aquifer material. Biodegradation 2010, 21, 793-800. [PubMed]

58. Da Silva, M.L.B.; Alvarez, P.J.J. Enhanced anaerobic biodegradation of benzene-toluene-ethylbenzenexylene-ethanol mixtures in bioaugmented aquifer columns. Appl. Environ. Microbiol. 2004, 70, 4720-4726.

59. Kimes, N.E.; Callaghan, A.V.; Aktas, D.R.; Smith, W.L.; Sunner, J.; Golding, B.T.; Drozdowska, M.; Hazen, T.C.; Suflita, J.M.; Morris, P.J. Metagenomic analysis and metabolite profiling of deep-sea sediments from the Gulf of Mexico following the Deepwater Horizon oil spill. Front. Microbiol. 2013, 4, 50.

60. Brow, C.N.; Johnson, R.O.; Johnson, R.L.; Simon, H.M. Assessment of anaerobic toluene biodegradation activity by bss A transcript/gene ratios. Appl. Environ. Microbiol. 2013, 79, 5338-5344.

61. Beller, H.R.; Kane, S.R.; Legler, T.C.; Alvarez, P.J.J. A real-time polymerase chain reaction method for monitoring anaerobic, hydrocarbon-degrading bacteria based on a catabolic gene. Environ. Sci. Technol. 2002, 36, 3977-3984. [CrossRef]

62. Oberding, L.K.; Gieg, L.M. Methanogenic paraffin biodegradation: Alkylsuccinate synthase gene quantification and dicarboxylic acid production. Appl. Environ. Microbiol. 2018, 84, e01773-17.

63. Pilloni, G.; Bayer, A.; Ruth-Anneser, B.; Fillinger, L.; Engel, M.; Griebler, C.; Lueders, T. Dynamics of hydrology and anaerobic hydrocarbon degrader communities in a tar-oil contaminated aquifer. Microorganisms 2019, 7,46 .

64. Müller, J.B.; Ramos, D.T.; Larose, C.; Fernandes, M.; Lazzarin, H.S.C.; Vogel, T.M.; Corseuil, H.X. Combined iron and sulfate reduction biostimulation as a novel approach to enhance BTEX and PAH source-zone biodegradation in biodiesel blend-contaminated groundwater. J. Hazard. Mater. 2017, 326, 229-236. [PubMed] 